\title{
DFT and Ab Initio Composite Methods: Investigation of Oxygen Fluoride Species
}

\author{
Zainab H. A. Alsunaidi ${ }^{1,2}$ and Angela K. Wilson ${ }^{1,2, *}$
}

${ }^{1}$ Department of Chemistry and Center for Advanced Scientific Computing and Modeling (CASCaM), University of North Texas, 1155 Union Circle, \#305070, Denton, Texas 76203-5017, USA.

${ }^{2}$ Department of Chemistry, Michigan State University, 578 S Shaw Lane, East Lansing, Michigan, 48824.

* Corresponding author. E-mail address: wilson@chemistry.msu.edu (A. K. Wilson). 


\title{
DFT and Ab Initio Composite Methods: Investigation of Oxygen Fluoride Species
}

\author{
Zainab H. A. Alsunaidi ${ }^{1,2}$ and Angela K. Wilson ${ }^{1,2, *}$ \\ 1 Department of Chemistry and Center for Advanced Scientific Computing and Modeling \\ (CASCaM), University of North Texas, 1155 Union Circle, \#305070, Denton, Texas 76203-5017, \\ USA. \\ 2 Department of Chemistry, Michigan State University, 578 S Shaw Lane, East Lansing, \\ Michigan, 48824. \\ *Corresponding author. E-mail address: wilson@chemistry.msu.edu (A. K. Wilson).
}

\begin{abstract}
The capability of ccCA, G3, and G3B3 for the prediction of the enthalpies of formation of oxygen fluoride species was evaluated. In addition to these composite methods, the performance of M06 and M06-2X in conjunction with the correlation consistent basis sets (aug-cc-pVnZ), where $n=\mathrm{D}, \mathrm{T}, \mathrm{Q}$, was also examined for predicting the structures and enthalpies of formation of oxygen fluoride species. A set of various oxygen fluorides were considered, including $\mathrm{FO}_{\mathrm{x}}$ radicals, $\mathrm{FO}_{\mathrm{x}} \mathrm{H}$, and $\mathrm{FO}_{\mathrm{x}} \mathrm{F}$, where $\mathrm{x}=1-3$. The effects of basis set size and spin contamination were also considered.
\end{abstract}

\section{KEYWORDS}

oxygen fluorides

enthalpies of formation

M06

M06-2X

composite methods

ccCA

\section{INTRODUCTION}

The oxygen fluorides have attracted interest because they can be employed as propellants in the rocket industry and can be used as strong fluorinating and oxidizing agents. In addition, oxygen fluorides play a role as intermediates in atmospheric chemistry and are believed to make a minor contribution to the destruction of ozone [1-6]. The source of fluorine in the atmosphere originates from the decomposition of chlorofluorocarbons (CFCs) and their radical fragments, but most of the atmospheric fluorine is in the form of hydrogen fluoride (HF). Hydrogen fluoride is formed from the fast reaction of a fluorine atom with methane and water vapor [5,7]. Although the role of fluorine in ozone depletion is minor, the percentage of fluorine in the atmosphere has been reported to be increasing with time [8-10]. Thus, accurate thermochemical properties are required for modeling fluorine compounds in the study of atmospheric reactions. Due to the unstable nature of oxygen fluorides, experimental measurements of the energetic properties have been limited. Computational approaches can aid in understanding such systems. 
Investigating the structural properties of the oxygen fluorides has been a challenge to the computational chemical community, particularly for FOO and FOOF. The F-O bond in oxygen fluorides is a covalent bond between two highly electronegative atoms where both atoms contain lone pair electrons. Therefore, the F-O bond exhibits strong electron lone pair - lone pair repulsion and can become very long in molecules such as FOO and FOOF $(\sim 0.2 \AA$ longer than the F-O bond in FOF) [11,12], requiring consideration of high-level electron correlation methods. In FOO and FOOF, the $\mathrm{O}-\mathrm{O}$ bond length is similar to that in the $\mathrm{O}_{2}$ molecule but $\sim 0.2$ $\AA$ shorter than the O-O bond length in HOOH [11]. The unusual geometry of FOO and FOOF presented a computational difficulty for electronic structure methods, which led to numerous investigations of oxygen fluorides using a variety of methods to study their structures and energetic properties [13-30]. Many methods have been unsuccessful in predicting the right structure for oxygen fluorides, such as FOO, FOOO, and FOOF, with respect to the experimental geometries, as will be seen in the following sections.

As a full literature review of these efforts is outside the scope of this paper, a number of significant and recent investigations are highlighted. The FOO structure and enthalpy of formation $\left(\Delta \mathrm{H}_{f}^{\circ}, 298\right)$ have been computed by Francisco et al. [16] using Møller-Plesset perturbation theory (MP2, MP3, and MP4), complete active space self-consistent field (CASSCF), and quadratic configuration interaction [QCISD(T)] in conjunction with Pople's basis sets. The study found that all MPn methods underestimated the FO bond length by $>0.2 \AA$. QCISD(T)/6-31G(d) yielded the best FO bond length that is only shorter by $0.002 \AA$ from the experimental length (expt. $r_{\mathrm{e}}(\mathrm{F}-\mathrm{O})=1.649 \pm 0.013 \AA$ [31], where $r_{\mathrm{e}}$ indicates an equilibrium structure), whereas the best CASSCF description of the F-O bond length is $0.8 \AA$ shorter than experiment. Francisco's study reported an enthalpy of formation at $0 \mathrm{~K}$ for FOO of $8.9 \pm 3 \mathrm{kcal}$ $\mathrm{mol}^{-1}$ by using isodesmic and isogyric reaction schemes using QCISD(T)/6-311G(d,p) results [16]. Ventura and Kieninger's [26] study on FOO concluded that B3LYP/6-311++G(3df, 3pd) is a reliable method to describe structures and predict reaction enthalpies for molecules involving F-O bonds. Studies by Denis [30,32,33] found that the inclusion of the full treatment of the triple excitation [CCSDT instead of CCSD(T)] overcame the spin contamination problem presented in $\mathrm{UCCSD}(\mathrm{T})$, hence CCSDT predicted an accurate structure and energetics of the FOO molecule. Karton et al.,[20] reported the $\Delta \mathrm{H}_{f, 298}^{\circ}$ of $\mathrm{FOO}$ of $5.87 \pm 0.16 \mathrm{kcal} \mathrm{mol}^{-1}$ in excellent agreement with experiment $\left(6.1 \pm 0.5 \mathrm{kcal} \mathrm{mol}^{-1}\right)$ using the high-level computationally demanding W4 method [34]. A recent theoretical study by Feller et al. [15] obtained a correct structure of FOO using R/UCCSD(T)/aug-cc-pVTZ level of theory and with a calculated value of $\Delta \mathrm{H}_{f, 298}^{\circ}$ of $6.4 \pm$ $0.7 \mathrm{kcal} \mathrm{mol}^{-1}$ using a composite approach that is based on coupled cluster theory with up to quadruple excitations. The difference in the uncertainties estimated by Karton's $(5.87 \pm 0.16 \mathrm{kcal}$ $\left.\mathrm{mol}^{-1}[20]\right)$ and Feller $\left(6.4 \pm 0.7 \mathrm{kcal} \mathrm{mol}^{-1}[15]\right)$ imputes to their different approaches. While W4 estimates uncertainties based on the performance of a set of 25 small molecules [20], Feller's approach uses molecule-by-molecule criteria to calculate the estimated uncertainties [15].

The structure and the $\Delta \mathrm{H}_{f, 298}^{\circ}$ of FOOF have been studied extensively with a broad variety of quantum chemical methods. The computational challenge in the FOOF structure arises from the anomeric delocalization effect that exists in FOOF between the oxygen lone pair and the antibonding orbital of the F-O bond [29]. Although CCSD(T)/aug-cc-pVTZ [15] and B3LYP/6-311++G(2d) [18] can provide a qualitatively correct geometry for FOOF, very few methods used in previous work reproduced the experimental FOOF structure. In fact, a local density functional (LDF) paired with numerical and Gaussian basis sets [35] and the local 
SVWN functional paired with 6-311++G(2d) [18] were two methods that predicted the closest $r_{e}$ of the F-O bond compared to experiment, with LDF being superior. LDF predicted F-O and O-O bond lengths that are $0.01 \AA$ and $0.001 \AA$ off from experimental geometries $\left(r_{s}(\mathrm{~F}-\mathrm{O})=1.575 \pm\right.$ $0.003 \AA$ and $\left.r_{s}(\mathrm{O}-\mathrm{O})=1.217 \pm 0.003 \AA[11]\right)$, respectively. LDF predicted this good description for FOOF likely due to the high and evenly distributed electron density in FOOF, as justified in Ref. 34. MP2, MP3, and MP4 with different size and type of basis sets, on the other hand, predicted incorrect geometries for FOOF with respect to experiment, however MP6 at the complete basis set (CBS) limit predicted an accurate geometry [29]. Not only is the structure of FOOF problematic but its $\Delta \mathrm{H}_{f, 298}^{\circ}$ has also been difficult to predict. The calculated $\Delta \mathrm{H}_{f, 298}^{\circ}$ of FOOF using even high-level ab initio methods has a large deviation from the experimental value reported in the NIST-JANAF thermochemical table $\left(4.6 \pm 0.5 \mathrm{kcal} \mathrm{mol}^{-1}\right)[36,37]$. The $\Delta \mathrm{H}_{f, 298}^{\circ}$ 's reported by Karton et al. [20] is $7.84 \pm 0.18 \mathrm{kcal} \mathrm{mol}^{-1}$ and $8.21 \pm 0.18 \mathrm{kcal} \mathrm{mol}^{-1}$ using W4 energies at the $\operatorname{CCSD}(\mathrm{T}) / \mathrm{cc}-\mathrm{pVQZ}$ and experimental geometries, respectively. The most recent value of the $\Delta \mathrm{H}_{f, 298}^{\circ}$ of FOOF is $6.4 \pm 0.7 \mathrm{kcal} \mathrm{mol}^{-1}$ and was calculated using a coupled clusterbase composite approach [15]. These are only a few examples of this large deviation from experiment.

Predicting the conformational structure of FOOO has also been challenging. Frecer et al. [38] investigated the FOOO that formed by $\mathrm{F}+\mathrm{O}_{3}$ reaction and found that $\mathrm{FO}(\mathrm{O})_{2}$ is the most stable structure with F-O being a weak bond (3.671 $)$ ). However, FOOO was observed later as a stabilized intermediate in dilute mixtures of $\mathrm{F}_{2}$ and $\mathrm{O}_{3}$ in solid argon by FT-IR spectroscopy [39].

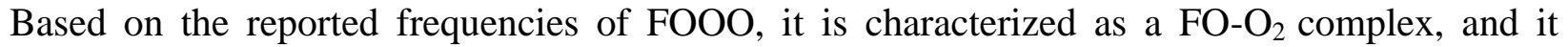
cannot be a weak van der Waals complex [39], which differs from Frecer's stable structure [38], mentioned above. Quantum chemical studies by Li et al. [40] and Peiró-García et al. [41] of the F $+\mathrm{O}_{3}$ reaction mechanisms using MP2/6-31G(d) and QCISD/6-311+G(d,p), respectively, also could not predict the FOOO ground state complex observed experimentally in the argon matrix [39]. A geometry optimization and frequency calculations of FOOO were performed by Roohi et al. [25] at the CCSD/aug-cc-pVDZ, CCSD/6-311+G(d), and QCISD/aug-cc-pVDZ levels of theory. Roohi's study [25] showed that the planar FOOO with dihedral angle of $0.0^{\circ}$ is the most stable structure, with its calculated frequencies agreeing well with the reported experimental frequencies [39]. No $\Delta \mathrm{H}^{\circ}{ }_{f, 298}$ for FOOO has been previously reported, to our knowledge. The structure of the corresponding hydride FOOOH has only been studied previously by MINDO [42] and by MP2/6-31G(d) [43]. As MP2 theory has encountered difficulty for calculating the FO and the $\mathrm{OO}$ bond lengths, an additional investigation of the $\mathrm{FOOOH}$ structure has to be done.

While methods such as CCSDT and QCISD are computationally demanding, ab initio composite methods have been developed to circumvent the computational demands of such methods. One such approach, the correlation consistent Composite Approach (ccCA) [44-46], is a method that has been demonstrated to be practical and reliable for the prediction of thermochemical properties, such as enthalpies of formation, ionization potentials, and electron affinities. The targeted accuracy of ccCA for main group molecules is to yield a mean absolute deviation of approximate chemical accuracy, $1 \mathrm{kcal} \mathrm{mol}^{-1}$ at reduced computational cost. This is in contrast to coupled cluster-based composite methods, which generally strive for a chemical accuracy of $\pm 0.24 \mathrm{kcal} \mathrm{mol}^{-1}$, such as the W4 composite method and the approach used by Feller et al. [15]. Because the performance of ccCA for a variety of halogen oxides and their related hydrides has not been examined in detail, it is of our interest to consider the utility of ccCA in describing oxygen fluorides, such as FOO, FOOF, and FOOO. 
Density functionals provide another option, as, overall, functionals have a lower formal computational scaling than post-HF methods such as CCSD(T) and CCSDT, though DFT predictions such as for enthalpies of formation, in general, do not reach the accuracies achievable by composite methods, such as ccCA. Thus, they are system dependent methods and are worth considering for each system. For example, the Minnesota density functionals M06 [47] and M062X [47] were used by Meyer and Kass, [48] in conjunction with the correlation consistent basis sets [49-51] to assess their performance for predicting the $\Delta \mathrm{H}_{f, 298}^{\circ}$ 's of a set of chlorine oxides and related hydrides $\left(\mathrm{ClO}_{\mathrm{x}}\right.$ and $\mathrm{ClO}_{\mathrm{x}} \mathrm{H}$, where $\left.\mathrm{x}=1-4\right)$ with respect to the $\Delta \mathrm{H}_{f, 298}^{\circ}$ 's of W4 method [34]. The capability of G3 [52] and G3B3 [53] for calculating $\Delta \mathrm{H}_{f, 298}^{\circ}$ 's of chlorine oxides were also investigated in the same study [48] The main findings from the Meyer and Kass study are that M06 $\Delta \mathrm{H}^{\circ}$, 298's were found to differ by an average of $1.3 \mathrm{kcal} \mathrm{mol}^{-1}$ from the W4 $\Delta \mathrm{H}_{f, 298}^{\circ}$ 's, while M06-2X resulted in larger error $\left(6.2 \mathrm{kcal} \mathrm{mol}^{-1}\right)$. G3 and G3B3 $\Delta \mathrm{H}_{f, 298}^{\circ}$ 's yielded an average error of $4.6 \mathrm{kcal} \mathrm{mol}^{-1}$ and $6.5 \mathrm{kcal} \mathrm{mol}^{-1}$, respectively. The author attributed the large errors of G3 and G3B3 $\Delta \mathrm{H}_{f, 298}^{\circ} \mathrm{s}$ to their poor predicted geometries. Although M06 and M06-2X functionals were examined for the prediction of the $\Delta \mathrm{H}_{f, 298}^{\circ}$ 's of chlorine oxides, the capability of M06 and M06-2X to predict structures and $\Delta \mathrm{H}_{f, 298}^{\circ}$ 's has not been assessed for other halogen oxides. Thus, it is of interest to evaluate these functionals for oxygen fluoride species, as well as examine the performance of G3 and G3B3 methods for these systems. G3 and G3B3 are used here, largely, as they were included in the Mayer and Kass study [48]. Though G4 is a more modern method, beginning with an MP4 reference energy is a costly start, and as shown in previous studies, G4 predicts very similar energies as G3 [54,55].

In the present study, the reliability of ccCA, G3, and G3B3 for the prediction of the $\Delta \mathrm{H}_{f}^{\circ}$, 298 's of oxygen fluoride species was evaluated. In addition to these composite methods, the performance of M06 and M06-2X was also examined for predicting the structures and enthalpies of formation of oxygen fluoride species. A set of various oxygen fluorides were considered in this study, including FO, FOO, FOOO, and the related hydrides (FOH, FOOH, and FOOOH) and difluorides (FOF, FOOF, and FOOOF), where the $\Delta \mathrm{H}_{f, 298}^{\circ}$ 's of FOOO and FOOOH have not been reported previously. The effects of basis set size and spin contamination were also considered. For comparison, the $\Delta \mathrm{H}_{f}^{\circ}$, 298's of chlorine oxides and related hydrides have been provided, whereas full theoretical investigations for chlorine oxides and related hydrides can be found in the Meyer and Kass study and references therein [48].

\section{COMPUTATIONAL METHODOLOGY}

All calculations were performed using the Gaussian 09 software package [56]. The hybrid-meta-generalized gradient approximation (HMGGA) Minnesota functionals (M06 [47] and M06-2X [47]) in conjunction with the augmented correlation consistent polarized valence basis sets (aug-cc-pVnZ), where $n=\mathrm{D}, \mathrm{T}, \mathrm{Q}$, [49-51] were used to optimize the structures of all molecules under investigation. The tight- $d$ correlation consistent basis set of Dunning et al., [57] aug-cc-pV $(n+d) \mathrm{Z}$, where $n=\mathrm{D}, \mathrm{T}, \mathrm{Q}$, were used for chlorine. Frequency calculations were performed using M06 and M06-2X with each of the three basis sets to ensure that the structure is a stationary point. The enthalpies of formation for these structures were determined at the same level of theory. ccCA, G3, and G3B3, were also applied to predict the enthalpies of formation. In ccCA, geometry optimization and vibrational frequencies calculations are performed using B3LYP/aug-cc-pVTZ [44]. The harmonic vibrational frequencies are then corrected using a scale 
factor of 0.989 as recommended in Ref. 44. The remaining steps in ccCA involve a series of single point energy calculations performed using the B3LYP/aug-cc-pVTZ geometry [44]. Several variants of ccCA can be used, which vary by the means used to extrapolate the MP2 energy (MP2/aug-cc-pVoZ) to the CBS limit [44]. ccCA-S3 and ccCA-S4 utilize Schwartz's inverse cubic and quartic extrapolation scheme, respectively [58]. ccCA-P utilizes Peterson's mixed Gaussian/exponential extrapolation scheme [59] and ccCA-PS3 is an average of ccCA-P and ccCA-S3. In ccCA, several additive terms are combined with the MP2/CBS reference energy (extrapolated energy) including terms recovering the correlation energy beyond MP2, the corevalence and core-core correlation energies, and scalar-relativistic effects. All of these components are then added together, along with the zero point energy (ZPE) and an atomic spinorbit correction, to provide the final ccCA energy. G3 [52] and G3B3 [53] both are composite methods that involve the same series of single point energy calculations though based upon different geometries. The geometry optimization in G3 is at the MP2(FULL)/6-31G(d) level of theory, while G3B3 uses the B3LYP/6-31G(d) level of theory. For open-shell systems (radicals) such as FOO and FOOO, which show a degree of spin contamination, RO-ccCA [60] and G3RAD [61] energies were obtained and used to calculate their $\Delta \mathrm{H}_{f, 298}^{\circ}$ 's. Gaussian 09 was used to determine these energies. The mean absolute deviations (MADs) of the calculated $\Delta \mathrm{H}_{f, 298}^{\circ}$ 's were determined for all of the utilized methods with respect to the experimental values, unless otherwise noted.

\section{RESULTS AND DISCUSSION}

\subsection{Structures}

The structural parameters obtained by M06 and M06-2X for all of the species are listed in Table 1. The optimized structures at the B3LYP/aug-cc-pVTZ, MP2(full)/6-31G(d), and B3LYP/6-31G(d) levels, which are used for geometry optimizations in ccCA, G3, and G3B3, respectively, were also considered (shown in Table 1). Experimental structural parameters of FO [22], FOO [31], FOF [12], FOOF [11], and FOH [17], have been reported and were utilized as reference data to determine the performance of the considered methods. To the authors' knowledge no experimental observations have been reported for the geometric parameters of FOOH, FOOO, and FOOOF. Thus, for these molecules theoretical results from rigorous methods such as coupled cluster are presented to calibrate the considered methods (CCSD(T)/TZ2P structure for FOOH [21], CCSD/6-311+G(d) structure for FOOO [25], and CCSD(T)/cc-pVTZ for FOOOF [19]).

The F-O bond length calculated by M06 and M06-2X for all set of molecules showed a systematic decrease in length when using the correlation consistent basis set family going from aug-cc-pVDZ, aug-cc-pVTZ, to aug-cc-pVQZ (Table 1). However, this decrease in the bond length while increasing basis set size does not occur for the $\mathrm{O}-\mathrm{O}$ bond length as shown in Table 1, and can be dependent on the density functional being utilized. Both M06 and M06-2X underestimated the F-O and $\mathrm{O}-\mathrm{O}$ bond lengths with respect to the corresponding experimental values. M06-2X predicted shorter F-O bond lengths and longer FO-O bond lengths than M06. The average difference between the aug-cc-pVTZ F-O bond lengths and the aug-cc-pVQZ F-O bond lengths is $0.005 \AA$ for M06 and it is $0.002 \AA$ for M06-2X, and for the FO-O bond length it is $0.003 \AA$ for both functionals whereas the aug-cc-pVDZ bond lengths are generally longer. Yet, the M06/aug-cc-pVDZ and M06-2X/aug-cc-pVDZ predicted the closest geometries to the 
reference data with average errors in the F-O bond length of $0.032 \AA$ and $0.062 \AA$, respectively. Thus, increasing the basis set size will not always give the better structures for the systems under investigation. For open-shell species, such as FO, FOO, and FOOO, the degree of spin contamination resulting from the mixing of higher spin states into the wavefunction was calculated, as high spin contamination results in incorrect geometries and energies. Previous studies showed a high degree of spin contamination when studying FOO using other methods, such as MP2 [16,26]. No spin contamination was found when calculating FO, but it was present when calculating FOO and FOOO. The expectation values of the total spin, $\left\langle\mathrm{S}^{2}\right\rangle$, are listed in Table 2, where the optimal value for these radicals is $\left\langle\mathrm{S}^{2}\right\rangle=0.75$. The effect of spin contamination becomes appreciable as the deviation of $\left\langle\mathrm{S}^{2}\right\rangle$ from 0.75 increases, and this deviation decreases with increasing the size of the basis sets, as shown in Table 2. Both UM06 and UM06-2X suffer from spin contamination associated with FOO (small) and FOOO (severe), as shown in Table 2. This error was corrected by using the restricted open-shell density functionals as shown in Table 1. ROM06 and ROM06-2X provided better structural parameters with respect to the reference data for FOO and FOOO than what UM06 and UM062X predicted. Thus, the ROM06 and ROM06-2X geometries were used later to calculate the enthalpies of formation. FOOOF was found to exist in two conformers. Both have very similar geometries but differ in the dihedral angles. One conformer has $d(\mathrm{OOOF})=91.3^{\circ}$ and the other one has $d(\mathrm{OOOF})=82.0^{\circ}$ [19]. Because the energy difference between the two conformers at the $\operatorname{CCSD}(\mathrm{T}) / \mathrm{cc}-\mathrm{pVTZ}$ level is very small, $0.24 \mathrm{kcal} \mathrm{mol}^{-1}$, with the $d(\mathrm{OOOF})=82.0^{\circ}$ conformer having the lowest energy [19], only one conformer was included in the molecule test set. M06$2 \mathrm{X}$ described the structure of FOOOF better than M06 when compared to the CCSD(T) structure. Overall the geometries predicted by M06 are in better agreement with the reference data than M06-2X, although both functionals generally underestimated the F-O and the O-O bond lengths. Thus, for this set of molecules, doubling the amount of Hartree-Fock exchange from M06 to M06-2X does not improve the results.

As shown in Table 1, the F-O bond lengths obtained by B3LYP/aug-cc-pVTZ are in very good agreement (MAD of $0.01 \AA$ ) with respect to the reference data, with the exception of the F$\mathrm{O}$ bond distance(s) in FOO and FOOF. The difference in F-O bond lengths is more than $0.01 \AA$ $(0.018 \AA$ in FOO and $0.049 \AA$ in FOOF) compared to experimental values. Although B3LYP/aug-cc-pVTZ did not predict very accurate bond lengths for FOO and FOOF, it provided a qualitatively correct description of the structures of these two molecules. The capability of B3LYP to describe the geometries has been noticed previously for some of the oxygen fluorides [26,35]. Quite similarly, the calculated F-O bond lengths at the B3LYP/6-31G(d) level were in very good agreement with respect to the reference data; however, not only is the F-O bond length underestimated in FOO and in FOOF (by $0.065 \AA$ in FOO and $0.075 \AA$ in FOOF), but also the F$\mathrm{O}$ bond distance in FOOH was underestimated by about $0.016 \AA$ using B3LYP/6-31G(d) in comparison to the reference data. Additionally, when using the 6-31G(d) basis set, the average error for B3LYP increased from $0.01 \AA$ (obtained when using an aug-cc-pVTZ basis set) to 0.02 $\AA$. Thus, again B3LYP with the small basis set $6-31 G(d)$ is not enough to describe peroxide systems, such as FOO, FOOF, and FOOH. B3LYP in conjunction with aug-cc-pVTZ also resulted in the least average error of $0.01 \AA$ (from the reference data) for the O-O bond length compared to other methods. The effect of spin contamination for open shell systems using UB3LYP has been tested and the total spin operators $\left\langle S^{2}\right\rangle$ are presented in Table 2, for each level of theory. The $\left\langle\mathrm{S}^{2}\right\rangle$ values for FOO show that the use of UB3LYP at either basis set levels 
does not result in spin contamination, whereas for FOOO, both UB3LYP/aug-cc-pVTZ and UB3LYP/6-31G(d) levels resulted in large deviation from the optimal value $\left\langle S^{2}\right\rangle=0.75$. Consequently, the ROB3LYP is used to predict the geometry for FOOO, which is in agreement with the structure predicted by CCSD [25], as shown in Table 1. For FOOOF, B3LYP was able to predict the two conformers with $d(\mathrm{OOOF})=91.3^{\circ}$ and with $d(\mathrm{OOOF})=82.0^{\circ}$ and the $\mathrm{B} 3 \mathrm{LYP}$ $\mathrm{F}-\mathrm{O}$ and $\mathrm{O}-\mathrm{O}$ bond lengths agree well with the $\operatorname{CCSD}(\mathrm{T})$ bond lengths.

The predicted geometries for FOF, FOH, and FOOH by MP2(full)/6-31g(d) agree well with the reference data within a $0.01 \AA$ difference. However, MP2(full)/6-31g(d) predicted a 0.1 $\AA$ shorter F-O bond and a $0.1 \AA$ longer O-O bond for FOOF compared to experimental bond lengths, this large difference in the bond lengths was also found previously using MP2/6-31g** [43]. Likewise, the F-O and O-O bond lengths predicted by MP2(full)/6-31g(d) for FOOOF are $0.08 \AA$ and $0.05 \AA$ shorter than $\operatorname{CCSD}(\mathrm{T})$ results, indicating that this level of theory is not enough to describe the peroxide's geometry. For the open-shell systems FOO and FOOO, the UMP2 method could not provide converged geometries due to large spin contamination.

As mentioned earlier for $\mathrm{FOOOH}$, no reliable theoretical or experimental geometries have been reported. Based on the success of B3LYP/aug-cc-pVTZ method in predicting the FOOOF geometry compared to the CCSD(T)/cc-pVTZ, the B3LYP/aug-cc-pVTZ geometry for $\mathrm{FOOOH}$ is considered as the most reliable structure. For this compound, only one conformer $\left.d(\mathrm{FOOO})=-87.4^{\circ}\right)$ is found to be a stable structure. The B3LYP/6-31G(d) structure of FOOOH is quite similar to the structure at the B3LYP/aug-cc-pVTZ level, with a large difference of 0.03 $\AA$ in the FO-O bond length. M06 and M06-2X generally underestimated the bond lengths of FOOOH as compared to the B3LYP/aug-cc-pVTZ geometries. MP2 (full)/6-31g(d) predicted shorter F-O bond length and longer FO-O bond length than the B3LYP/aug-cc-pVTZ.

As a result of the above discussion, M06 and M06-2X are not recommended methods for predicting the geometries of oxygen fluorides and related hydrides and difluorides. MP2 performed well for most of the closed-shell compounds with the exception of the peroxides. The geometries obtained by B3LYP/aug-cc-pVTZ, shown in Figure 1, result in the lowest deviation from the reference data among the considered methods. As shown in Figure 1, using B3LYP/aug-cc-pVTZ supports conclusions from previous studies [12,17,31] that FOO, FOF, and FOH are bent with bond angles of $111.2^{\circ}, 103.9^{\circ}$, and $98.6^{\circ}$, respectively. Different bond angles indicate that the bond angle opens more as the repulsion between bonds increases. Similarly, FOOF and FOOH have dihedral angles of $88.2^{\circ}$ and $85.0^{\circ}$, respectively, in order to minimize the repulsion between bonds. FOOOF and FOOOH display a zigzag shape with $d(\mathrm{FOOO})=93.6^{\circ}$, and $d(\mathrm{FOOO})=-87.4^{\circ}$, respectively. In contrast to all the peroxide systems, the stable conformer of FOOO is when $d(\mathrm{FOOO})=0.0^{\circ}$. Intermolecular dispersion forces might be the cause of the stable FOOO structure.

\subsection{Enthalpies of Formation $\left(\Delta H_{f, 298}^{\circ}\right)$}

To provide a comparison between the performance of the utilized methods on chlorine oxide and oxygen fluoride species, the $\Delta \mathrm{H}_{f, 298}^{\circ}$ 's of chlorine oxides and related hydrides were determined using M06/aug-cc-pVQZ, M06-2X/aug-cc-pVQZ, ccCA-S3, G3, and G3B3 and are listed in Table 3 The MADs of the considered methods with respect to experiment for predicting $\Delta \mathrm{H}_{f, 298}^{\circ}$ 's are provided in Table 3 as well. These MADs are 1.1 (ccCA-S3), 2.1 (M06), 2.5 (M06-2X), 2.3 (G3), and 3.5 (G3B3) kcal mol-1 . The MAD of ccCA-S3 indicates that ccCA is a 
reliable method in predicting energetics for chlorine oxides. M06 resulted in a MAD of $2.1 \mathrm{kcal}$ mol $^{-1}$ for the calculated $\Delta \mathrm{H}^{\circ}$, 298's of chlorine oxides, which is $0.9 \mathrm{kcal} \mathrm{mol}^{-1}$ greater than the MAD (1.2 kcal mol $\left.{ }^{-1}\right)$ that resulted from the calculations done by Meyer and Kass [48]. This small difference arises from the use of a temperature correction approach that reduces the energy contributed from the low vibrational frequency modes as pointed out in Meyer and Kass study [47, 60]. In the present study, however, scale factors of 0.9853 (M06) and 0.9733 (M06-2X) [69] were used for the correction of the anharmonic vibrational frequencies in the computations. The $\Delta \mathrm{H}_{f, 298}^{\circ}$ 's calculated by M06 for chlorine oxides in the present study are in good agreement with the experimental values with the exception of $\mathrm{ClO}_{3}$, which is known to be problematic for not only computational methods but also for experiments, as demonstrated by the error bar associated with the experimental $\Delta \mathrm{H}_{f, 298}^{\circ}\left( \pm 3 \mathrm{kcal} \mathrm{mol}^{-1}\right)$ [70-72], as compared with smaller uncertainties for many main group species. Only ccCA-S3 and G3 predict the $\Delta \mathrm{H}_{f, 298}^{\circ}$ of $\mathrm{ClO}_{3}$ within the experimental uncertainty. The $\Delta \mathrm{H}_{f, 298}^{\circ}$ 's obtained by $\mathrm{G} 3$ are in relatively good agreement with the experiments $\left(\mathrm{MAD}=2.3 \mathrm{kcal} \mathrm{mol}^{-1}\right.$ ), yet the $\mathrm{ClO}_{2} \Delta \mathrm{H}_{f, 298}^{\circ}$ predicted by G3 overestimated the experimental value by $\sim 4 \mathrm{kcal} \mathrm{mol}^{-1}$. Similar to G3, M06-2X achieved a MAD of $2.5 \mathrm{kcal} \mathrm{mol}^{-1}$, while the MAD for G3B3 was larger (MAD of $3.2 \mathrm{kcal} \mathrm{mol}^{-1}$ ). Therefore, ccCA results in the lowest MAD from experiment for the prediction of energetic properties of chlorine oxides, followed by M06.

The $\Delta \mathrm{H}_{f}^{\circ}$, 298's for all of the oxygen fluoride species included in this study were calculated using M06 and M06-2X in conjunction with aug-cc-pVDZ, aug-cc-pVTZ, and aug-ccpVQZ at $298 \mathrm{~K}$ using the atomization energy approach and the results are shown in Table 4. A systematic decrease in the $\Delta \mathrm{H}_{f, 298}^{\circ}$ values as the size of the basis set increases is observed, since the basis set with larger zeta $(\xi)$ level recovers more energy, as shown in Table 4. The differences between energies determined using M06/aug-cc-pVTZ $\Delta \mathrm{H}_{f}^{\circ}, 298$ 's and those determined using M06/aug-cc-pVQZ $\Delta \mathrm{H}^{\circ}$, 298's is $0.1-1.1 \mathrm{kcal} \mathrm{mol}^{-1}$ with an average difference of $0.5 \mathrm{kcal} \mathrm{mol}^{-1}$, whereas the differences between energies determined using M06-2X/aug-ccpVTZ $\Delta \mathrm{H}_{f, 298}^{\circ}$ 's and those determined using M06-2X/aug-cc-pVQZ $\Delta \mathrm{H}_{f, 298}^{\circ}$ 's is $0.3-1.9 \mathrm{kcal}$ $\mathrm{mol}^{-1}$ with an average difference of $1.2 \mathrm{kcal} \mathrm{mol}^{-1}$. To evaluate the reliability of the utilized methods in calculating $\Delta \mathrm{H}_{f, 298}^{\circ}$ 's, the following reference data was used: experimental $\Delta \mathrm{H}_{f, 298}^{\circ}$ values for FO, FOO, FOF, FOOF and FOH; the CCSD(T)/ANO4 $\Delta \mathrm{H}_{f, 298}^{\circ}$ value for FOOH; and the extrapolated $\operatorname{CCSD}(\mathrm{T}) / \mathrm{aug}-\mathrm{cc}-\mathrm{pV}(\mathrm{T}, \mathrm{Q}) \mathrm{Z} \Delta \mathrm{H}_{f, 298}^{\circ}$ value for FOOOF. For FOOO and FOOOH neither experimental nor theoretical $\Delta \mathrm{H}_{f, 298}^{\circ}$ values are available. The MADs of the calculated $\Delta \mathrm{H}_{f, 298}^{\circ}$ 's with respect to the reference data were computed and provided in Table 4. Because of the well-known challenges of FOOF $[13,20,21,28]$, the MAD was also calculated without FOOF. For ccCA, the ccCA-S3 variant was selected as it results in the lowest MAD for the $\Delta \mathrm{H}_{f, 298}^{\circ}$ 's of oxygen fluoride species with respect to the reference data as shown in Table 5 as compared with the other ccCA variants.

The calculated $\Delta \mathrm{H}_{f, 298}^{\circ}$ 's of FO by ccCA, M06, M06-2X, G3, G3B3 are within the reported experimental uncertainty $\left( \pm 2.4 \mathrm{kcal} \mathrm{mol}^{-1}\right)$, as shown in Table 6 . The $\Delta \mathrm{H}_{f, 298}^{\circ}$ 's of FO calculated by G3 and G3B3 are the nearest to the reported experimental value, while the $\Delta \mathrm{H}_{f, 298}^{\circ}$ calculated by M06 deviated the most by $2.0 \mathrm{kcal} \mathrm{mol}^{-1}$, but is still within the experimental uncertainty. The $\mathrm{FO} \Delta \mathrm{H}_{f, 298}^{\circ}$ 's predicted by ccCA is also in very good agreement with experiment. For $\mathrm{FOH}$, the $\Delta \mathrm{H}_{f, 298}^{\circ}$ 's calculated by ccCA is found to be the closet to the reported experimental value, while G3 and G3B3 provide $\Delta \mathrm{H}_{f, 298}^{\circ}$ 's that are 1.6 and $1.9 \mathrm{kcal} \mathrm{mol}^{-1}$, 
respectively, less than the experimental uncertainty. M06 and M06-2X underestimate the $\Delta \mathrm{H}_{f}^{\circ}$, 298 's of $\mathrm{FOH}$ by 5.46 and $4.56 \mathrm{kcal} \mathrm{mol}^{-1}$, respectively, with respect to the experimental value. The ccCA $\Delta \mathrm{H}_{f, 298}^{\circ}$ of FOF is within the experimental error bar. G3 and G3B3 predict $\Delta \mathrm{H}_{f, 298}^{\circ}$ 's of 6.5 and $6.8 \mathrm{kcal} \mathrm{mol}^{-1}$, which are greater than the experimental uncertainty by 0.1 and $0.4 \mathrm{kcal}$ $\mathrm{mol}^{-1}$, respectively. M06 predicts a $\Delta \mathrm{H}_{f, 298}^{\circ}$ of FOF that is $3.2 \mathrm{kcal} \mathrm{mol}^{-1}$ outside of the experimental uncertainty, while the $\Delta \mathrm{H}_{f, 298}^{\circ}$ calculated by M06-2X is $2.3 \mathrm{kcal} \mathrm{mol}^{-1}$ outside of the experimental uncertainty.

For FOO, RO-ccCA and G3B3 give $\Delta \mathrm{H}_{f, 298}^{\circ} \mathrm{s}$ that are outside the experimental error by 0.9 and $0.4 \mathrm{kcal} \mathrm{mol}^{-1}$, respectively. These results demonstrate the utility of ccCA and G3B3 in predicting the FOO $\Delta \mathrm{H}_{f, 298}^{\circ}$. G3-RAD, one of the G3 versions developed for open-shell systems, is used instead of $\mathrm{G} 3$ to calculate the $\Delta \mathrm{H}_{f}^{\circ}$, 298's of the radicals FOO and FOOO. The G3-RAD $\Delta \mathrm{H}_{f, 298}^{\circ}$ of FOO is also in good agreement with experiment. The calculated $\Delta \mathrm{H}_{f, 298}^{\circ}$ for FOO using ROM06 is above experimental value by $2.9 \mathrm{kcal} \mathrm{mol}^{-1}$, whereas the $\Delta \mathrm{H}_{f, 298}^{\circ}$ calculated by ROM06-2X is $10.6 \mathrm{kcal} \mathrm{mol}^{-1}$ greater than experiment. This large deviation can be explained by the poor geometry obtained using these M06 and M06-2X.

For $\mathrm{FOOH}$, the $\mathrm{CCSD}(\mathrm{T}) / \mathrm{ANO} 4 \Delta \mathrm{H}_{f, 298}^{\circ}$ which is $-10.4 \pm 1.0 \mathrm{kcal} \mathrm{mol}{ }^{-1}$ [21], is being used as a reference value for this molecule. $\mathrm{G} 3$ and G3B3 predict $\Delta \mathrm{H}_{f, 298}^{\circ}$ 's of $\mathrm{FOOH}$ of -10.3 and $-10.2 \mathrm{kcal} \mathrm{mol}^{-1}$, respectively, which are in excellent agreement with the CCSD(T) value. Conversely, the ccCA $\Delta \mathrm{H}_{f, 298}^{\circ}$ value of $\mathrm{FOOH}$ is $-11.7 \mathrm{kcal} \mathrm{mol}^{-1}$, which is higher than the $\operatorname{CCSD}(\mathrm{T})$ value by $1.3 \mathrm{kcal} \mathrm{mol}^{-1}$. Based on the fact that oxygen fluoride molecules are considered highly correlated molecules, accounting for the core correlation correction in the method is highly important. Thus, ccCA $\Delta \mathrm{H}_{f, 298}^{\circ}$ 's can be more accurate than the CCSD(T) energies because ccCA energies includes core-valence and core-core correction terms, whereas the reported $\mathrm{CCSD}(\mathrm{T})$ results used the frozen-core approximation [21]. G3B3 includes the high level correction term (HLC) in the energy. The HLC is calculated based on empirical parameters and it is added to the G3 energy to reduce the error between theory and experiment. Without the HLC the G3B3 $\Delta \mathrm{H}_{f, 298}^{\circ}$ deviates by $\sim 7.0 \mathrm{kcal} \mathrm{mol}^{-1}$ from the CCSD(T) value. M06 and M06-2X both underestimate the $\Delta \mathrm{H}_{f, 298}^{\circ}$ of $\mathrm{FOOH}$ by 2.6 and $1.0 \mathrm{kcal} \mathrm{mol}^{-1}$, respectively. For FOOF, the ccCA $\Delta \mathrm{H}_{f, 298}^{\circ}$ value lies $3.6 \mathrm{kcal} \mathrm{mol}^{-1}$ outside the error bar of the value reported by NISTJANAF [36,37]. G3 and G3B3 predict $\Delta \mathrm{H}_{f, 298}^{\circ}$ 's that are greater than experimental error bar by 4.2 and $3.8 \mathrm{kcal} \mathrm{mol}^{-1}$, respectively. M06 and M06-2X give $\Delta \mathrm{H}_{f, 298}^{\circ}$ 's larger than experiment by 6.6 and $10.9 \mathrm{kcal} \mathrm{mol}^{-1}$, respectively. Several previous high-level theoretical studies have pointed out the discrepancy between experimental and calculated $\Delta \mathrm{H}_{f, 298}^{\circ} \mathrm{s}$, and suggested that the experiment to be revisited [15,20,21,28]. For example, high level methods predicted $\Delta \mathrm{H}_{f, 298}^{\circ}$ of FOOF of $9.6 \pm 0.9 \mathrm{kcal} \mathrm{mol}^{-1}$ (iCAS-CI+Q) [15], $8.7 \pm 2.0 \mathrm{kcal} \mathrm{mol}^{-1}$ (CCSD(T)/ANO4) [21], $7.84 \pm 0.18 \mathrm{kcal} \mathrm{mol}^{-1}$ (W4) [20], and $7.3 \mathrm{kcal} \mathrm{mol}^{-1}$ (B3PW91/aug-cc-pVQZ) [28]. In addition, from this work the ccCA value of the $\Delta \mathrm{H}_{f, 298}^{\circ}$ of FOOF is $8.7 \mathrm{kcal} \mathrm{mol}^{-1}$. Thus, the $\Delta \mathrm{H}_{f, 298}^{\circ}$ 's provided by theoretical approaches is between 7-9 kcal mol${ }^{-1}$, whereas the experimental value is $4.6 \pm 0.5 \mathrm{kcal} \mathrm{mol}^{-1}$. Because of this large and consistent discrepancy, the MAD of the $\Delta \mathrm{H}_{f, 298}^{\circ}$ 's is calculated with and without FOOF.

RO-ccCA, G3-RAD, ROM06, and ROM06-2X were employed to calculate the $\Delta \mathrm{H}_{f, 298}^{\circ}$ for FOOO and the predicted $\Delta \mathrm{H}_{f, 298}^{\circ}$ 's are listed in Table 6. Due to the lack of reference data for FOOO, the $\Delta \mathrm{H}_{f, 298}^{\circ}$ of ccCA for FOOO $\left(31.0 \mathrm{kcal} \mathrm{mol}^{-1}\right)$ is considered the most accurate based 
on the previous successes of ccCA in predicting energetic properties (MAD of $1.01 \mathrm{kcal} \mathrm{mol}^{-1}$ using ccCA-PS3 for main group molecules (G03/05 test set)) [44]. G3-RAD also predicts a very close value to the ccCA value $\left(30.1 \mathrm{kcal} \mathrm{mol}^{-1}\right)$. However, including empirical parameters makes G3-RAD a system-dependent method. Thus, the RO-ccCA value is recommended. The computed $\Delta \mathrm{H}_{f, 298}^{\circ}$ for FOOO using ROM06 is $5.7 \mathrm{kcal} \mathrm{mol}^{-1}$ greater than the RO-ccCA value. M06-2X predicts very high $\Delta \mathrm{H}_{f, 298}^{\circ}$ 's for FOOO compared to the other methods. For FOOOH, the calculated $\Delta \mathrm{H}_{f, 298}^{\circ}$ 's of ccCA is considered the reference data for the same reason previously mentioned. The $\Delta \mathrm{H}_{f, 298}^{\circ}$ of ccCA for FOOOH $\left(-1.6 \mathrm{kcal} \mathrm{mol}^{-1}\right)$ is chemically rational since formation of hydride is usually exothermic with fluoride lowering its stability. In addition, G3B3 predicts as exothermic $\Delta \mathrm{H}_{f, 298}^{\circ}$ as ccCA, but greater by $1.3 \mathrm{kcal} \mathrm{mol}^{-1}$. G3 and M06 and M06-2X overestimated the $\Delta \mathrm{H}_{f, 298}^{\circ}$ of $\mathrm{FOOOH}$ by $1.8,4.2$, and $4.5 \mathrm{kcal} \mathrm{mol}^{-1}$, respectively, with respect to the ccCA value. Finally, ccCA successfully predicts the $\Delta \mathrm{H}_{f, 298}^{\circ}$ of FOOOF with only a 0.2 $\mathrm{kcal} \mathrm{mol}^{-1}$ deviation from the extrapolated $\operatorname{CCSD}(\mathrm{T}) / \mathrm{aug}-\mathrm{cc}-\mathrm{pV}(\mathrm{T}, \mathrm{Q}) \mathrm{Z}$ value calculated previously by Huang et al.,[19] where other methods such as G2 and G96PW91/D95(3df) predicted $\Delta \mathrm{H}_{f, 298}^{\circ}$ 's that are $>7.0 \mathrm{kcal} \mathrm{mol}^{-1}$ higher than the $\operatorname{CCSD}(\mathrm{T})$ value [73]. Here G3B3 $\Delta \mathrm{H}^{\circ}, 298$ is also in good agreement with the $\operatorname{CCSD}(\mathrm{T})$ value, with a deviation of only $0.7 \mathrm{kcal}$ $\mathrm{mol}^{-1}$ between the two, but G3 $\Delta \mathrm{H}_{f, 298}^{\circ}$ differs by $1.2 \mathrm{kcal} \mathrm{mol}^{-1}$. This difference between G3B3 and G3 results typically comes from geometry optimization, with MP2 found to be insufficient to describe the structure of dioxygen fluoride species. M06 and M06-2X again overestimated the enthalpy of formation of FOOOF by $4.3 \mathrm{kcal} \mathrm{mol}^{-1}$ with respect to the CCSD(T) value.

The MADs of the calculated $\Delta \mathrm{H}_{f, 298}^{\circ}$ 's for all the utilized methods with respect to the reference data were computed and provided in Table 6. The MADs of M06 and M06-2X as shown in Table 6 are 4.0 and $5.2 \mathrm{kcal} \mathrm{mol}^{-1}$ (3.5 and $4.3 \mathrm{kcal} \mathrm{mol}^{-1}$ without FOOF), respectively. Thus, compared to the chlorine oxides in Table 3, M06 and M06-2X do not perform well for oxygen fluoride species. That can be attributed to the poor geometries obtained by M06 and M06-2X. Because of the deficiencies in the M06 and M06-2X computed geometries, single point M06 and M06-2X energy calculations were performed using the B3LYP/aug-cc-pVTZ geometries to examine the performances of M06 and M06-2X for oxygen fluorides energy calculations. $\Delta \mathrm{H}_{f, 298}^{\circ}$ and MAD's were calculated and listed in Table 7. However, no improvement is noticed in the M06 and M06-2X $\Delta \mathrm{H}_{f, 298}^{\circ} \mathrm{s}$ when using B3LYP geometries. That supports our conclusion that M06 and M06-2X are not considered reliable methods to predict structures and energetic properties for oxygen fluorides. G3 and G3B3 (including the G3-RAD values) perform well with MAD's of $1.5 \mathrm{kcal} \mathrm{mol}^{-1}$ for both methods $\left(0.9 \mathrm{kcal} \mathrm{mol}^{-1}\right.$ for both methods without FOOF). This performance is not surprising taking into account the inclusion of the HLC term in the G3 and G3B3 energy. For example, the G3B3 $\Delta \mathrm{H}_{f, 298}^{\circ}$ of FO without the HLC term is $30.3 \mathrm{kcal} \mathrm{mol}^{-1}$, a value that is greater by $3.8 \mathrm{kcal} \mathrm{mol}^{-1}$ than the $\mathrm{G} 3 \mathrm{~B} 3 \Delta \mathrm{H}_{f, 298}^{\circ}$ listed in Table 6. The MAD of the G3 and G3B3 methods $\left(1.5 \mathrm{kcal} \mathrm{mol}^{-1}\right)$ is much smaller for the oxygen fluorides than for the chlorine oxides $\left(2.3 \mathrm{kcal} \mathrm{mol}^{-1}\right.$ for $\mathrm{G} 3$ and $3.5 \mathrm{kcal} \mathrm{mol}^{-1}$ for G3B3), so G3 and G3B3 perform better for oxygen fluorides than for chlorine oxides. The MAD of ccCA-S3 is $1.4 \mathrm{kcal} \mathrm{mol}^{-1}\left(0.9 \mathrm{kcal} \mathrm{mol}^{-1}\right.$ without FOOF) for oxygen fluorides and is $1.1 \mathrm{kcal}$ $\mathrm{mol}^{-1}$ for chlorine oxides. This indicates a capability of ccCA to predict reliable energetic properties for halogen oxides.

In addition, a comparison between the calculated $\Delta \mathrm{H}_{f, 298}^{\circ}$ 's in this study and the recent ATcT values of the $\Delta \mathrm{H}^{\circ}$, 298's [74,75] of FO, FOH, FOF, FOO, FOOF, and FOOOF are 
examined. The ATcT tables use artificial intelligence algorithms to reduce the uncertainties in the experimentally measured $\Delta \mathrm{H}_{f, 298}^{\circ} \mathrm{s}$ by combining experimental and highly accurate theoretical thermochemical data [74,75]. As shown in Table 8, the uncertainties of the ATcT values of FO, FOH, FOF, and FOO decreased in comparison to the NIST-JANAF values (Table $6)$. Thus, to evaluate our methods against the ATcT values, the MADs of the calculated $\Delta \mathrm{H}_{f}^{\circ}$, 298's for all the utilized methods with respect to the ATcT values were computed and provided in Table 8. The MADs of ccCA-S3, M06, M06-2X, G3, and G3B3 were all lowered by 0.5-0.9 kcal $\mathrm{mol}^{-1}$ in comparison with the MADs shown in Table 6 (with ccCA-S3 providing the lowest MAD, at $0.6 \mathrm{kcal} \mathrm{mol}^{-1}$ ). The large difference in the MADs is likely attributed to the large difference between the ATcT $\Delta \mathrm{H}_{f, 298}^{\circ}$ for FOOF $\left(8.04 \pm 0.09 \mathrm{kcal} \mathrm{mol}^{-1}\right)$ and the NIST-JANAF value $\left(4.6 \pm 0.5 \mathrm{kcal} \mathrm{mol}^{-1}\right)$.

\section{CONCLUSION}

The capability of ccCA, G3, and G3B3 for the prediction of the enthalpies of formation of oxygen fluoride species was evaluated. In addition, the performance of M06 and M06-2X in conjunction with the correlation consistent basis sets (aug-cc-pVnZ), where $n=\mathrm{D}, \mathrm{T}, \mathrm{Q}$, was also examined for predicting the structures and enthalpies of formation of oxygen fluoride species. An important finding from this study is that though M06 and M06-2X are useful functionals for many main group species (including chlorine oxides), M06 and M06-2X were less successful in the prediction of reasonable structures and $\Delta \mathrm{H}_{f, 298}^{\circ}$ 's for oxygen fluorides, oxygen difluorides, and related hydrides. This could be generalized to systems containing F-O and/or O-O bonds (e.g. peroxides and polyoxides). Geometries predicted by B3LYP/aug-ccpVTZ are generally in good agreement with the listed reference data. When calculating the enthalpies of formation, ccCA-S3 provides the lowest MAD $\left(1.4 \mathrm{kcal} \mathrm{mol}^{-1}\right.$ with respect to the reference data; $0.9 \mathrm{kcal} \mathrm{mol}^{-1}$ excluding FOOF) without any parameterized energies. While ccCA-S3 provides the smallest MAD of the four different CBS extrapolation formulas considered for this set of molecules, other ccCA variants, such as ccCA-PS3, have been found to be useful in previous studies [44,54]. G3 and G3B3 achieved a MAD that is greater than ccCAS3 by only $0.1 \mathrm{kcal} \mathrm{mol}^{-1}$ with respect to the reference data while incorporating an empirical parameter that is intended to reduce the overall MAD of G3 and G3B3 (or MAD of $0.9 \mathrm{kcal} \mathrm{mol}^{-}$ ${ }^{1}$ excluding FOOF, which is identical to ccCA-S3 in this case). The performance of G3 and G3B3 for chlorine oxides is not as good as for oxygen fluorides. ccCA-S3 predictions of the $\Delta \mathrm{H}_{f, 298}^{\circ}$ 's of both the oxygen fluorides and of the chloride oxides species are in good agreement with the experimental values. In addition, when comparing the calculated $\Delta \mathrm{H}_{f, 298}^{\circ}$ 's to the ATcT values, ccCA-S3 provides the lowest MAD $\left(0.6 \mathrm{kcal} \mathrm{mol}^{-1}\right)$ in comparison to the other methods including in this study. The enthalpies of formation for FOOO and FOOOH are predicted to be 31.0 and $-1.6 \mathrm{kcal} \mathrm{mol}^{-1}$, respectively, by the ccCA-S3 method. Overall, the use of the correlation consistent Composite Approach (ccCA) is recommended for such systems, with promise for other halogen systems and peroxides.

\section{ACKNOWLEDGMENTS}

This material is based on work supported by the National Science Foundation under grant CHE1213874. Computational resources were provided by Texas' Academic Computing Services at the University of North Texas for the use of the UNT Research Clusters. 


\section{REFERENCES}

[1] M.J. Prather, M.B. McElroy, S.C. Wofsy, Reductions in ozone at high concentrations of stratospheric halogens, Nature. 312 (1984) 227-231.

[2] M.J. Prather, R.T. Watson, Stratospheric ozone depletion and future levels of atmospheric chlorine and bromine, Nature. 344 (1990) 729-734.

[3] S.P. Sander, R.R. Friedl, Y.L. Yung, Rate of formation of the ClO dimer in the polar stratosphere: implications for ozone loss, Science 245 (1989) 1095-1098.

[4] S. Solomon, Progress towards a quantitative understanding of Antarctic ozone depletion, Nature. 347 (1990) 347-354.

[5] A.R. Ravishankara, A.A. Turnipseed, N.R. Jensen, S. Barone, M. Mills, C.J. Howard, S. Solomon, Do Hydrofluorocarbons Destroy Stratospheric Ozone?, Science. 263 (1994) 7175.

[6] A. Parrish, R.L. De Zafra, P.M. Solomon, J.W. Barrett, E.R. Carlson, Chlorine Oxide in the Stratospheric Ozone Layer: Ground-Based Detection and Measurement, Science. 211 (1981) 1158-1161.

[7] A.J. Colussi, M.A. Grela, Rate of the reaction between oxygen monofluoride and ozone: Implications for the atmospheric role of fluorine, Chem. Phys. Lett. 229 (1994) 134-138.

[8] R. Zander, C.P. Rinsland, E. Mahieu, M.R. Gunson, C.B. Farmer, M.C. Abrams, M.K.W. $\mathrm{Ko}$, Increase of carbonyl fluoride $\left(\mathrm{COF}_{2}\right)$ in the stratosphere and its contribution to the 1992 budget of inorganic fluorine in the upper stratosphere, J. Geophys. Res. Atmos. 99 (1994) 16737-16743.

[9] R. Nassar, P.F. Bernath, C.D. Boone, S.D. McLeod, R. Skelton, K.A. Walker, C.P. Rinsland, P. Duchatelet, A global inventory of stratospheric fluorine in 2004 based on Atmospheric Chemistry Experiment Fourier transform spectrometer (ACE-FTS) measurements, J. Geophys. Res. Atmos. 111 (2006) D22313.

[10] A.T. Brown, M.P. Chipperfield, N.A.D. Richards, C. Boone, P.F. Bernath, Global stratospheric fluorine inventory for 2004-2009 from Atmospheric Chemistry Experiment Fourier Transform Spectrometer (ACE-FTS) measurements and SLIMCAT model simulations, Atmos. Chem. Phys. 14 (2014) 267-282.

[11] R.H. Jackson, The microwave spectrum, structure, and dipole moment of dioxygen difluoride, J. Chem. Soc. (1962) 4585-4592.

[12] L. Pierce, N. Di Cianni, R.H. Jackson, Centrifugal distortion effects in asymmetric rotor molecules. I. Quadratic potential constants and average structure of oxygen difluoride from the ground-state rotational spectrum, J. Chem. Phys. 38 (1963) 730-739.

[13] D. Feller, D.A. Dixon, Coupled cluster theory and multireference configuration interaction study of FO, $\mathrm{F}_{2} \mathrm{O}, \mathrm{FO}_{2}$, and FOOF, J. Phys. Chem. A. 107 (2003) 9641-9651.

[14] M. Alcami, O. Mó, M. Yáñez, I.L. Cooper, The performance of density-functional theory in challenging cases: halogen oxides, J. Chem. Phys. 112 (2000) 6131-6140.

[15] D. Feller, K.A. Peterson, D.A. Dixon, Refined theoretical estimates of the atomization energies and molecular structures of selected small oxygen fluorides, J. Phys. Chem. A. 114 (2010) 613-623.

[16] J.S. Francisco, Y. Zhao, W.A. Lester, I.H. Williams, Theoretical studies of the structure and thermochemistry of $\mathrm{FO}_{2}$ radical: comparison of Møller-Plesset perturbation, complete-active-space self-consistent-field, and quadratic configuration interaction methods, J. Chem. Phys. 96 (1992) 2861-2867.

[17] L. Halonen, T.K. Ha, Equilibrium structure and anharmonic force field of hypofluorous 
acid (HOF), J. Chem. Phys. 89 (1988) 4885-4888.

[18] B.S. Jursic, The density functional theory investigation of the equilibrium structures of OOF, FOOF, $\mathrm{OOF}_{2}$, and FOOOF, J. Mol. Struct. THEOCHEM. 366 (1996) 97-101.

[19] M.-J. Huang, J.D. Watts, Theoretical characterization of the $\mathrm{F}_{2} \mathrm{O}_{3}$ molecule by coupledcluster methods, J. Phys. Chem. A. 114 (2010) 10197.

[20] A. Karton, S. Parthiban, J.M.L. Martin, Post-CCSD(T) ab Initio thermochemistry of halogen oxides and related hydrides $\mathrm{XOX}, \mathrm{XOOX}, \mathrm{HOX}, \mathrm{XO}_{\mathrm{n}}$, and $\mathrm{HXO}_{\mathrm{n}}(\mathrm{X}=\mathrm{F}, \mathrm{Cl})$, and evaluation of DFT methods for these systems, J. Phys. Chem. A. 113 (2009) 48024816.

[21] T.J. Lee, J.E. Rice, C.E. Dateo, The varying nature of fluorine oxygen bonds, Mol. Phys. 89 (1996) 1359-1372.

[22] C.E. Miller, B.J. Drouin, The $\mathrm{X}_{1}{ }^{2} \Pi_{3 / 2}$ and $\mathrm{X}_{2}{ }^{2} \Pi_{1 / 2}$ potential energy surfaces of FO, J. Mol. Spectrosc. 205 (2001) 312-318.

[23] R.M. Minyaev, T.N. Gribanova, Structure and stability of halogen oxoacids $\mathrm{XO}_{\mathrm{n}} \mathrm{H}(\mathrm{X}=\mathrm{F}$, $\mathrm{Cl} ; \mathrm{n}=1-4)$ : a quantum chemistry study, Russ. J. Inorg. Chem. 49 (2004) 579-586.

[24] P.A.G. O’Hare, A.C. Wahl, Oxygen monofluoride (OF, $\left.{ }^{2} \Pi\right)$ : Hartree-Fock wavefunction, binding energy, ionization potential, electron affinity, dipole and quadrupole moments, and spectroscopic constants. A comparison of theoretical and experimental results, J. Chem. Phys. 53 (1970) 2469-2478.

[25] H. Roohi, B. Mackiabadi, Conformations of $\mathrm{O}_{3}-\mathrm{F}$ 1:1 complexes. An ab initio study, Bull. Chem. Soc. Jpn. 80 (2007) 1914-1919.

[26] O.N. Ventura, M. Kieninger, The $\mathrm{FO}_{2}$ radical: a new success of density functional theory, Chem. Phys. Lett. 245 (1995) 488-497.

[27] Y. Zhao, J.S. Francisco, Ab initio studies of the structure and thermochemistry of FO radicals, Chem. Phys. Lett. 167 (1990) 285-290.

[28] M. Kieninger, M. Segovia, O.N. Ventura, A discrepancy between experimental and theoretical thermochemical characterization of some oxygen fluorides, Chem. Phys. Lett. 287 (1998) 597-600.

[29] E. Kraka, Y. He, D. Cremer, Quantum chemical descriptions of FOOF: the unsolved problem of predicting its equilibrium geometry, J. Phys. Chem. A. 105 (2001) 3269-3276.

[30] P.A. Denis, O.N. Ventura, CCSDT study of the fluoroperoxyl radical, FOO, Chem. Phys. Lett. 385 (2004) 292-297.

[31] C. Yamada, E. Hirota, The infrared diode laser spectrum of the $v_{2}$ band of the $\mathrm{FO}_{2}$ radical, J. Chem. Phys. 80 (1984) 4694-4700.

[32] P.A. Denis, O.N. Ventura, Corrigendum to "CCSDT study of the fluoroperoxyl radical, FOO” [Chem. Phys. Lett. 385 (2004) 292-297], Chem. Phys. Lett. 395 (2004) 385-386.

[33] P.A. Denis, On the performance of CCSD(T) and CCSDT in the study of molecules with multiconfigurational character: halogen oxides, $\mathrm{HSO}, \mathrm{BN}$ and $\mathrm{O}_{3}$, Chem. Phys. Lett. 395 (2004) 12-20.

[34] A. Karton, E. Rabinovich, J.M.L. Martin, B. Ruscic, W4 theory for computational thermochemistry: in pursuit of confident sub-kJ/mol predictions, J. Chem. Phys. 125 (2006).

[35] D.A. Dixon, J. Andzelm, G. Fitzgerald, E. Wimmer, Density functional study of a highly correlated molecule, oxygen fluoride (FOOF), J. Phys. Chem. 95 (1991) 9197-9202.

[36] M.W. Chase, C.A. Davies, J.R. Downey, D.J. Frurip, R.A. McDonald, A.N. Syverud, JANAF Thermochemical Tables, 3rd ed, J. Phys. Chem. Ref. Data. 14 (1985). 
[37] M.W. Chase, NIST-JANAF Thermochemical Tables, 4th ed, J. Phys. Chem. Ref. Data. 2 (1998).

[38] V. Frecer, D.C. Jain, A.-M. Sapse, $\mathrm{Ab}$ initio calculations for $\mathrm{FO}_{3}, \mathrm{FO}_{3}^{+}$, and $\mathrm{FO}_{3}{ }^{-}$ complexes formed by fluorine with ozone, Struct. Chem. 9 (1998) 9-13.

[39] E.Y. Misochko, A. V. Akimov, C.A. Wight, Infrared spectroscopic observation of the stabilized intermediate complex $\mathrm{FO}_{3}$ formed by reaction of mobile fluorine atoms with ozone molecules trapped in an argon matrix, J. Phys. Chem. A. 103 (1999) 7972-7977.

[40] L.-C. Li, J. Wang, X. Wang, A.-M. Tian, N.-B. Wong, Quantum chemical study of the reaction mechanism of ozone and methane with fluorine and chlorine atoms, Int. J. Quantum Chem. 87 (2002) 288-292.

[41] J. Peiró-García, I. Nebot-Gil, An ab initio study on the mechanism of the $\mathrm{F}+\mathrm{O}_{3} \rightarrow \mathrm{FO}+\mathrm{O}_{2}$ reaction: comparative reactivity study along the isoelectronic $\mathrm{NH}_{2}, \mathrm{OH}$ and $\mathrm{F}$ radicals series, Chem. Phys. Lett. 391 (2004) 195-199.

[42] C. Glidewell, Structure and conformation in molecular peroxides, J. Mol. Struct. 67 (1980) 35-44.

[43] B.M. Gimarc, M. Zhao, Oxygen ring strain energies revisited: effects of terminal atoms of the chain reference structure, J. Phys. Chem. 98 (1994) 1596-1600.

[44] N.J. DeYonker, B.R. Wilson, A.W. Pierpont, T.R. Cundari, A.K. Wilson, Towards the intrinsic error of the correlation consistent composite approach (ccCA), Mol. Phys. 107 (2009) 1107-1121.

[45] N.J. DeYonker, T. Grimes, S. Yockel, A. Dinescu, B. Mintz, T.R. Cundari, A.K. Wilson, The correlation-consistent composite approach: Application to the G3/99 test set, J. Chem. Phys. 125 (2006).

[46] N.J. DeYonker, T.R. Cundari, A.K. Wilson, The correlation consistent composite approach (ccCA): an alternative to the Gaussian- $n$ methods, J. Chem. Phys. 124 (2006).

[47] Y. Zhao, D. Truhlar, The M06 suite of density functionals for main group thermochemistry, thermochemical kinetics, noncovalent interactions, excited states, and transition elements: two new functionals and systematic testing of four M06-class functionals and 12 other function, Theor. Chem. Acc. 120 (2008) 215-241.

[48] M.M. Meyer, S.R. Kass, Experimental and theoretical gas-phase acidities, bond dissociation energies, and heats of formation of $\mathrm{HClO}_{x}, \mathrm{x}=1-4$, J. Phys. Chem. A. 114 (2010) 4086-4092.

[49] T.H. Dunning, Gaussian basis sets for use in correlated molecular calculations. I. The atoms boron through neon and hydrogen, J. Chem. Phys. 90 (1989) 1007-1023.

[50] D.E. Woon, T.H. Dunning, Gaussian basis sets for use in correlated molecular calculations. III. The atoms aluminum through argon, J. Chem. Phys. 98 (1993) 13581371.

[51] T.H. Dunning, K.A. Peterson, A.K. Wilson, Gaussian basis sets for use in correlated molecular calculations. X. The atoms aluminum through argon revisited, J. Chem. Phys. 114 (2001) 9244-9253.

[52] L.A. Curtiss, K. Raghavachari, P.C. Redfern, V. Rassolov, J.A. Pople, Gaussian-3 (G3) theory for molecules containing first and second-row atoms, J. Chem. Phys. 109 (1998) 7764-7776.

[53] A.G. Baboul, L.A. Curtiss, P.C. Redfern, K. Raghavachari, Gaussian-3 theory using density functional geometries and zero-point energies, J. Chem. Phys. 110 (1999) 76507657. 
[54] K.R. Jorgensen, A.K. Wilson, Enthalpies of formation for organosulfur compounds: atomization energy and hypohomodesmotic reaction schemes via ab initio composite methods, Comput. Theor. Chem. 991 (2012) 1-12.

[55] B.R. Wilson, N.J. DeYonker, A.K. Wilson, Prediction of hydrocarbon enthalpies of formation by various thermochemical schemes, J. Comput. Chem. 33 (2012) 2032-2042.

[56] M.J. Frisch, G.W. Trucks, H.B. Schlegel, G.E. Scuseria, M.A. Robb, J.R. Cheeseman, G. Scalmani, V. Barone, B. Mennucci, G.A. Petersson, H. Nakatsuji, M. Caricato, X. Li, H.P. Hratchian, A.F. Izmaylov, J. Bloino, G. Zheng, J.L. Sonnenberg, M. Hada, M. Ehara, K. Toyota, R. Fukuda, J. Hasegawa, M. Ishida, T. Nakajima, Y. Honda, O. Kitao, H. Nakai, T. Vreven, J.A. Montgomery Jr., J.E. Peralta, F. Ogliaro, M.J. Bearpark, J. Heyd, E.N. Brothers, K.N. Kudin, V.N. Staroverov, R. Kobayashi, J. Normand, K. Raghavachari, A.P. Rendell, J.C. Burant, S.S. Iyengar, J. Tomasi, M. Cossi, N. Rega, N.J. Millam, M. Klene, J.E. Knox, J.B. Cross, V. Bakken, C. Adamo, J. Jaramillo, R. Gomperts, R.E. Stratmann, O. Yazyev, A.J. Austin, R. Cammi, C. Pomelli, J.W. Ochterski, R.L. Martin, K. Morokuma, V.G. Zakrzewski, G.A. Voth, P. Salvador, J.J. Dannenberg, S. Dapprich, A.D. Daniels, Ö. Farkas, J.B. Foresman, J. V Ortiz, J. Cioslowski, D.J. Fox, Gaussian 09, (2009).

[57] K.A. Peterson, T.H. Dunning, Accurate correlation consistent basis sets for molecular core-valence correlation effects: The second row atoms Al-Ar, and the first row atoms BNe revisited, J. Chem. Phys. 117 (2002) 10548-10560.

[58] C. Schwartz, Importance of angular correlations between atomic electrons, Phys. Rev. 126 (1962) 1015-1019.

[59] K.A. Peterson, D.E. Woon, T.H. Dunning, Benchmark calculations with correlated molecular wave functions. IV. The classical barrier height of the $\mathrm{H}+\mathrm{H}_{2} \rightarrow \mathrm{H}_{2}+\mathrm{H}$ reaction, J. Chem. Phys. 100 (1994) 7410-7415.

[60] T.G. Williams, N.J. DeYonker, B.S. Ho, A.K. Wilson, The correlation consistent composite approach: the spin contamination effect on an MP2-based composite methodology, Chem. Phys. Lett. 504 (2011) 88-94.

[61] D.J. Henry, M.B. Sullivan, L. Radom, G3-RAD and G3X-RAD: modified Gaussian-3 (G3) and Gaussian-3X (G3X) procedures for radical thermochemistry, J. Chem. Phys. 118 (2003) 4849-4860.

[62] R.D. Amos, J.S. Andrews, N.C. Handy, P.J. Knowles, Open-shell Møller-Plesset perturbation theory, Chem. Phys. Lett. 185 (1991) 256-264.

[63] H.-J. Werner, P. J. Knowles, G. Knizia, F. R. Manby, M. Schütz, and others, MOLPRO, version 2006, a package of ab initio programs, (2006).

[64] P.J. Knowles, J.S. Andrews, R.D. Amos, N.C. Handy, J.A. Pople, Restricted MøllerPlesset theory for open-shell molecules, Chem. Phys. Lett. 186 (1991) 130-136.

[65] W.J. Lauderdale, J.F. Stanton, J. Gauss, J.D. Watts, R.J. Bartlett, Many-body perturbation theory with a restricted open-shell Hartree-Fock reference, Chem. Phys. Lett. 187 (1991) 21-28.

[66] W.J. Lauderdale, J.F. Stanton, J. Gauss, J.D. Watts, R.J. Bartlett, Restricted open-shell Hartree-Fock based many-body perturbation theory: theory and application of energy and gradient calculations, J. Chem. Phys. 97 (1992) 6606-6620.

[67] J.D. Watts, J. Gauss, R.J. Bartlett, Coupled-cluster methods with noniterative triple excitations for restricted open-shell Hartree-Fock and other general single determinant reference functions. Energies and analytical gradients, J. Chem. Phys. 98 (1993) 8718- 
8733.

[68] M.M. Meyer, Probing the Structure and Reactivity of Gaseous Ions. Ph.D. Dissertation, University of Minnesota, Minneapolis, MN, 2010.

[69] M.L. Laury, M.J. Carlson, A.K. Wilson, Vibrational frequency scale factors for density functional theory and the polarization consistent basis sets., J. Comput. Chem. 33 (2012)

[70] A.J. Colussi, M.A. Grela, Kinetics and thermochemistry of chlorine- and nitrogencontaining oxides and peroxides, J. Phys. Chem. 97 (1993) 3775-3779.

[71] T. Rathmann, R.N. Schindler, Ab initio calculations on the geometries and thermodynamic stabilities of chlorine trioxides, Chem. Phys. Lett. 190 (1992) 539-542.

[72] A. Rauk, E. Tschuikow-Roux, Y. Chen, M.P. McGrath, L. Radom, The possible role of chlorine trioxide isomers in relation to stratospheric ozone, J. Phys. Chem. 97 (1993) 7947-7954.

[73] X.-H. Ju, Z.-Y. Wang, X.-F. Yan, H.-M. Xiao, Density functional theory studies on dioxygen difluoride and other fluorine/oxygen binary compounds: availability and shortcoming, J. Mol. Struct. THEOCHEM. 804 (2007) 95-100.

[74] B. Ruscic, R.E. Pinzon, M.L. Morton, G. von Laszevski, S.J. Bittner, S.G. Nijsure, K.A. Amin, M. Minkoff, A.F. Wagner, Introduction to Active Thermochemical Tables: several "key" enthalpies of formation revisited, J. Phys. Chem. A. 108 (2004) 9979-9997.

[75] B. Ruscic, R.E. Pinzon, G. Von Laszewski, D. Kodeboyina, A. Burcat, D. Leahy, D. Montoy, A.F. Wagner, Active Thermochemical Tables: thermochemistry for the 21st century, J. Phys. Conf. Ser. 16 (2005) 561-570.

[76] S.P. Sander, R.R. Friedl, D.M. Golden, M.J. Kurylo, G.K. Moortgat, H. Keller-Rudek, P.H. Wine, A.R. Ravishankara, C.E. Kolb, M.J. Molina, B.J. Finlayson-Pitts, R.E. Huie, V.L. Orkin, Chemical kinetics and photochemical data for use in atmospheric studies, evaluation N. 15, JPL Publication 06-2, Jet Propulsion Laboratory, Pasadena, 2006.

[77] S.L. Nickolaisen, R.R. Friedl, S.P. Sander, Kinetics and mechanism of the chlorine oxide $\mathrm{ClO}+\mathrm{ClO}$ reaction: pressure and temperature dependences of the bimolecular and termolecular channels and thermal decomposition of chlorine peroxide, J. Phys. Chem. 98 (1994) 155-169.

[78] J.A. Joens, The dissociation energy of $\mathrm{OH}\left(\mathrm{X}^{2} \Pi_{3 / 2}\right)$ and the enthalpy of formation of $\mathrm{OH}\left(\mathrm{X}^{2} \Pi_{3 / 2}\right), \mathrm{ClOH}$, and $\mathrm{BrOH}$ from thermochemical cycles, J. Phys. Chem. A. 105 (2001) 11041-11044. 


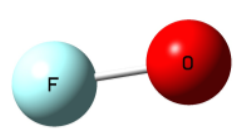

FO

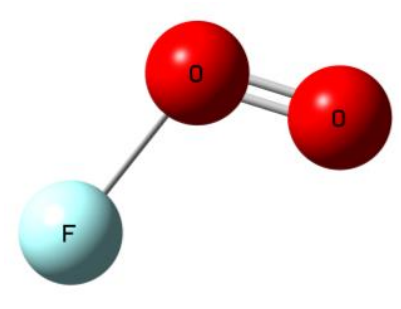

FOO

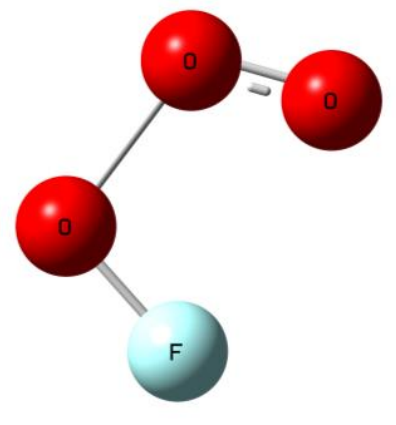

FOOO

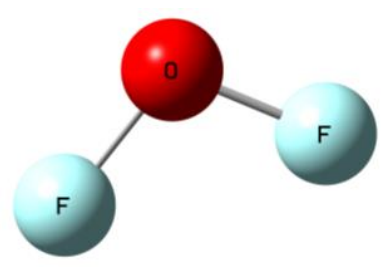

FOF

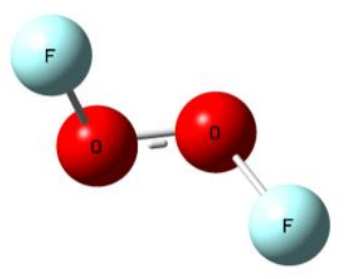

FOOF

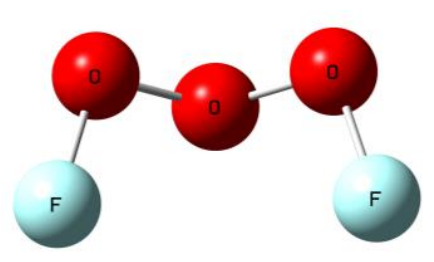

FOOOF

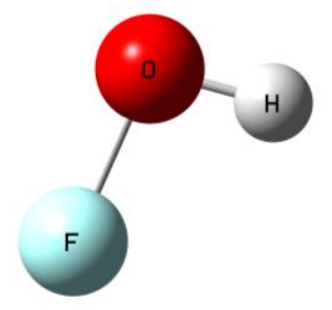

$\mathrm{FOH}$

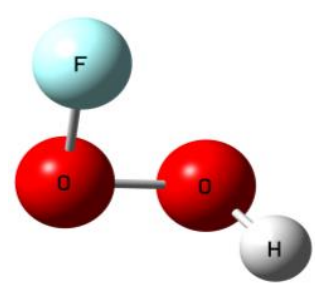

$\mathrm{FOOH}$

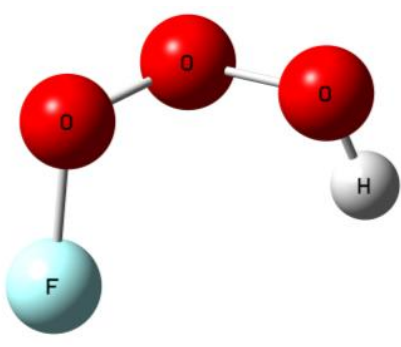

$\mathrm{FOOOH}$

Figure 1. B3LYP/aug-cc-pVTZ structures of the oxygen fluorides species included in this study. 
Table 1. Structural parameters of the oxygen fluoride species at different level of theories, bond lengths are in Angstroms and bond angles and dihedral angles are in degree.

\begin{tabular}{|c|c|c|c|}
\hline \multicolumn{4}{|c|}{$\mathrm{FO}$} \\
\hline Method/Basis set & $r(\mathrm{FO})$ & & \\
\hline M06/aug-cc-pVDZ & 1.332 & & \\
\hline M06/aug-cc-pVTZ & 1.328 & & \\
\hline M06/aug-cc-pVQZ & 1.324 & & \\
\hline M062X/aug-cc-pVDZ & 1.329 & & \\
\hline M062X/aug-cc-pVTZ & 1.329 & & \\
\hline M062X/aug-cc-pVQZ & 1.325 & & \\
\hline B3LYP/aug-cc-pVTZ & 1.351 & & \\
\hline B3LYP/6-31g(d) & 1.354 & & \\
\hline MP2(full)/6-31g(d) & 1.344 & & \\
\hline Experiment $\mathrm{t}^{\mathrm{a}}$ & 1.354 & & \\
\hline \multicolumn{4}{|c|}{$\mathrm{FOH}$} \\
\hline Method/Basis set & $r(\mathrm{FO})$ & $r(\mathrm{OH})$ & $a(\mathrm{FOH})$ \\
\hline M06/aug-cc-pVDZ & 1.408 & 0.973 & 99.1 \\
\hline M06/aug-cc-pVTZ & 1.405 & 0.969 & 99.2 \\
\hline M06/aug-cc-pVQZ & 1.401 & 0.966 & 99.3 \\
\hline M062X/aug-cc-pVDZ & 1.401 & 0.971 & 99.3 \\
\hline M062X/aug-cc-pVTZ & 1.400 & 0.968 & 99.4 \\
\hline M062X/aug-cc-pVQZ & 1.397 & 0.967 & 99.5 \\
\hline B3LYP/aug-cc-pVTZ & 1.430 & 0.971 & 98.6 \\
\hline $\mathrm{B} 3 \mathrm{~L} Y \mathrm{P} / 6-31 \mathrm{~g}(\mathrm{~d})$ & 1.434 & 0.977 & 97.8 \\
\hline MP2(full)/6-31g(d) & 1.444 & 0.979 & 97.1 \\
\hline Experiment $^{\mathrm{b}}$ & $1.4350 \pm 0.0031$ & $0.9657 \pm 0.0016$ & $97.54 \pm 0.50$ \\
\hline \multicolumn{4}{|c|}{ FOF } \\
\hline Method/Basis set & $r(\mathrm{FO})$ & $a(\mathrm{FOF})$ & \\
\hline M06/aug-cc-pVDZ & 1.380 & 103.5 & \\
\hline M06/aug-cc-pVTZ & 1.377 & 103.6 & \\
\hline M06/aug-cc-pVQZ & 1.374 & 103.7 & \\
\hline M062X/aug-cc-pVDZ & 1.376 & 102.9 & \\
\hline M062X/aug-cc-pVTZ & 1.374 & 103.0 & \\
\hline M062X/aug-cc-pVQZ & 1.371 & 103.1 & \\
\hline B3LYP/aug-cc-pVTZ & 1.403 & 103.9 & \\
\hline B3LYP/6-31g(d) & 1.409 & 103.9 & \\
\hline MP2(full)/6-31g(d) & 1.423 & 102.6 & \\
\hline Experiment $^{\mathrm{c}}$ & 1.412 & 103.1 & \\
\hline \multicolumn{4}{|c|}{ FOO } \\
\hline Method/Basis set & $r(\mathrm{FO})$ & $r(\mathrm{OO})$ & $a(\mathrm{FOO})$ \\
\hline M06/aug-cc-pVDZ & 1.811 & 1.177 & 110.7 \\
\hline M06/aug-cc-pVTZ & 1.752 & 1.171 & 110.6 \\
\hline M06/aug-cc-pVQZ & 1.747 & 1.170 & 110.7 \\
\hline ROM06/aug-cc-pVDZ & 1.589 & 1.182 & 110.6 \\
\hline ROM06/aug-cc-pVTZ & 1.580 & 1.178 & 110.6 \\
\hline ROM06/aug-cc-pVQZ & 1.572 & 1.178 & 110.7 \\
\hline M062X/aug-cc-pVDZ & 2.090 & 1.184 & 111.2 \\
\hline
\end{tabular}




\begin{tabular}{llll}
\hline M062X/aug-cc-pVTZ & 1.520 & 1.190 & 110.0 \\
M062X/aug-cc-pVQZ & 1.519 & 1.187 & 110.1 \\
ROM062X/aug-cc-pVDZ & 1.508 & 1.194 & 109.9 \\
ROM062X/aug-cc-pVTZ & 1.500 & 1.194 & 110.0 \\
ROM062X/aug-cc-pVQZ & 1.500 & 1.191 & 110.1 \\
B3LYP/aug-cc-pVTZ & 1.618 & 1.188 & 111.2 \\
B3LYP/6-31g(d) & 1.571 & 1.211 & 111.0 \\
MP2(full)/6-31g(d) & - & - & - \\
Experiment $^{\mathrm{d}}$ & $1.649 \pm 0.013$ & $1.200 \pm 0.013$ & $111.2 \pm 0.36$ \\
\hline
\end{tabular}

\begin{tabular}{|c|c|c|c|c|c|c|}
\hline \multicolumn{7}{|c|}{$\mathrm{FOOH}$} \\
\hline Method/Basis set & $r(\mathrm{FO})$ & $r(\mathrm{OO})$ & $r(\mathrm{OH})$ & $a(\mathrm{FOO})$ & $a(\mathrm{OOH})$ & $d(\mathrm{FOOH})$ \\
\hline M06/aug-cc-pVDZ & 1.447 & 1.343 & 0.977 & 105.9 & 104.0 & 85.5 \\
\hline M06/aug-cc-pVTZ & 1.438 & 1.346 & 0.972 & 105.9 & 103.9 & 85.2 \\
\hline M06/aug-cc-pVQZ & 1.434 & 1.343 & 0.970 & 106.0 & 104.0 & 85.4 \\
\hline M062X/aug-cc-pVDZ & 1.419 & 1.358 & 0.973 & 105.3 & 103.6 & 84.6 \\
\hline M062X/aug-cc-pVTZ & 1.415 & 1.361 & 0.970 & 105.4 & 103.6 & 84.6 \\
\hline M062X/aug-cc-pVQZ & 1.412 & 1.357 & 0.968 & 105.5 & 103.7 & 84.7 \\
\hline B3LYP/aug-cc-pVTZ & 1.470 & 1.365 & 0.974 & 106.3 & 103.7 & 85.0 \\
\hline B3LYP/6-31g(d) & 1.465 & 1.376 & 0.981 & 106.1 & 102.9 & 83.1 \\
\hline MP2(full)/6-31g(d) & 1.468 & 1.39 & 0.981 & 105.0 & 102.0 & 83.1 \\
\hline Experiment & - & - & - & - & - & - \\
\hline $\operatorname{CCSD}(\mathrm{T}) / \mathrm{TP} 2 \mathrm{Z}^{\mathrm{e}}$ & 1.481 & 1.393 & 0.969 & 105.4 & 101.9 & 84.5 \\
\hline \multicolumn{7}{|c|}{ FOOF } \\
\hline Method/Basis set & $r(\mathrm{FO})$ & $r(\mathrm{OO})$ & & $a(\mathrm{FOO})$ & & $d$ (FOOF) \\
\hline M06/aug-cc-pVDZ & 1.506 & 1.217 & & 108.6 & & 87.2 \\
\hline M06/aug-cc-pVTZ & 1.494 & 1.219 & & 108.5 & & 86.9 \\
\hline M06/aug-cc-pVQZ & 1.485 & 1.221 & & 108.6 & & 87.0 \\
\hline M062X/aug-cc-pVDZ & 1.426 & 1.285 & & 106.6 & & 85.9 \\
\hline M062X/aug-cc-pVTZ & 1.420 & 1.289 & & 106.7 & & 85.7 \\
\hline M062X/aug-cc-pVQZ & 1.419 & 1.286 & & 106.8 & & 85.8 \\
\hline B3LYP/aug-cc-pVTZ & 1.523 & 1.227 & & 109.3 & & 88.1 \\
\hline $\mathrm{B} 3 \mathrm{~L} Y \mathrm{P} / 6-31 \mathrm{~g}(\mathrm{~d})$ & 1.497 & 1.266 & & 108.3 & & 86.7 \\
\hline MP2(full)/6-31g(d) & 1.496 & 1.291 & & 106.9 & & 85.8 \\
\hline Experiment $\mathrm{f}^{\mathrm{f}}$ & $1.575 \pm 0.003$ & $1.217 \pm 0.003$ & & $109.5 \pm 0.5$ & & $87 \pm 0.5$ \\
\hline \multicolumn{7}{|c|}{ FOOO } \\
\hline Method/Basis set & $r(\mathrm{FO})$ & $r(\mathrm{FO}-\mathrm{O}), r(\mathrm{l}$ & $\mathrm{OO}-\mathrm{O})$ & $a(\mathrm{FOO}), a$ & OO) & $d(\mathrm{FOOO})$ \\
\hline M06/aug-cc-pVDZ & 1.338 & $2.469,1.196$ & & $97.8,110.8$ & & 0.0 \\
\hline M06/aug-cc-pVTZ & 1.335 & $2.408,1.191$ & & $93.0,106.5$ & & 0.0 \\
\hline M06/aug-cc-pVQZ & 1.331 & $2.449,1.189$ & & $92.4,105.9$ & & 0.0 \\
\hline ROM06/aug-cc-pVDZ & 1.357 & $1.704,1.192$ & & $100.2,110.1$ & & 0.0 \\
\hline ROM06/aug-cc-pVTZ & 1.354 & $1.687,1.189$ & & $100.9,110.5$ & & 0.0 \\
\hline ROM06/aug-cc-pVQZ & 1.350 & $1.681,1.188$ & & $101.1,110.7$ & & 0.0 \\
\hline M062X/aug-cc-pVDZ & 1.331 & $2.598,1.191$ & & $88.5,103.4$ & & 0.0 \\
\hline M062X/aug-cc-pVTZ & 1.333 & $2.537,1.187$ & & $90.4,105.6$ & & 0.0 \\
\hline M062X/aug-cc-pVQZ & 1.327 & $2.702,1.187$ & & $91.0,107.8$ & & 0.0 \\
\hline ROM062X/aug-cc-pVDZ & 1.360 & $1.589,1.204$ & & $103.3,112.1$ & & 0.0 \\
\hline ROM062X/aug-cc-pVTZ & 1.359 & $1.575,1.205$ & & $103.9,112.4$ & & 0.0 \\
\hline ROM062X/aug-cc-pVQZ & 1.356 & $1.573,1.203$ & & $104.0,112.5$ & & 0.0 \\
\hline B3LYP/aug-cc-pVTZ & 1.354 & $2.715,1.204$ & & $101.1,113.8$ & & 0.0 \\
\hline
\end{tabular}




\begin{tabular}{lllll} 
B3LYP/6-31g(d) & 1.360 & $2.504,1.211$ & $91.0,103.3$ & 0.0 \\
ROB3LYP/aug-cc-pVTZ & 1.379 & $1.709,1.201$ & $101.2,111.2$ & 0.0 \\
ROB3LYP/6-31g(d) & 1.380 & $1.710,1.214$ & $100.3,110.2$ & 0.0 \\
B97D/aug-cc-pVTZ & 1.385 & $1.842,1.204$ & $100.9,111.3$ & - \\
MP2(full)/6-31g(d) & - & - & - & - \\
Experiment & - & - & - & 0.0 \\
CCSD/6-311+G(d) & 1.378 & $1.745,1.200$ & $100.5,111.5$ & 0.0 \\
\hline
\end{tabular}

$\mathrm{FOOOH}$

\begin{tabular}{lllllll}
\hline Method/Basis set & $r(\mathrm{FO})$ & $\begin{array}{l}r(\mathrm{FO}-\mathrm{O}), \\
r(\mathrm{O}-\mathrm{OH})\end{array}$ & $r(\mathrm{OH})$ & $\begin{array}{l}a(\mathrm{FOO}), a(\mathrm{OOO}), \\
a(\mathrm{OOH})\end{array}$ & $d(\mathrm{FOOO})$ & $d(\mathrm{OOOH})$ \\
\hline M06/aug-cc-pVDZ & 1.483 & $1.290,1.427$ & 0.974 & $106.5,109.0,101.1$ & -85.8 & 91.7 \\
M06/aug-cc-pVTZ & 1.471 & $1.292,1.428$ & 0.970 & $106.5,109.0,101.1$ & -85.7 & 91.4 \\
M06/aug-cc-pVQZ & 1.466 & $1.291,1.424$ & 0.968 & $106.6,109.1,101.2$ & -85.6 & 91.8 \\
M062X/aug-cc-pVDZ & 1.427 & $1.331,1.406$ & 0.972 & $105.3,107.9,101.8$ & -84.0 & 91.4 \\
M062X/aug-cc-pVTZ & 1.423 & $1.333,1.407$ & 0.967 & $105.5,108.1,102,1$ & -84.0 & 90.1 \\
M062X/aug-cc-pVQZ & 1.421 & $1.330,1.403$ & 0.968 & $105.6,108.2,102.2$ & -83.9 & 90.3 \\
B3LYP/aug-cc-pVTZ & 1.502 & $1.303,1.461$ & 0.972 & $107.3,109.6,100.7$ & -87.4 & 96.0 \\
B3LYP/6-31g(d) & 1.485 & $1.331,1.454$ & 0.979 & $106.3,108.8,99.9$ & -84.9 & 89.0 \\
MP2(full)/6-31g(d) & 1.481 & $1.358,1.450$ & 0.981 & $104.9,107.5,99.7$ & -83.2 & 87.0 \\
Experiment & - & - & - & - & & - \\
\hline
\end{tabular}

FOOOF

\begin{tabular}{lllll}
\hline Method/Basis set & $r(\mathrm{FO})$ & $r(\mathrm{OO})$ & $a(\mathrm{FOO}), a(\mathrm{OOO})$ & $d(\mathrm{FOOO})$ \\
\hline M06/aug-cc-pVDZ & 1.419 & 1.355 & $106.2,109.0$ & \pm 93.0 \\
M06/aug-cc-pVTZ & 1.413 & 1.355 & $106.2,109.1$ & \pm 92.5 \\
M06/aug-cc-pVQZ & 1.410 & 1.353 & $106.3,109.2$ & \pm 92.4 \\
M062X/aug-cc-pVDZ & 1.403 & 1.360 & $105.3,108.1$ & \pm 90.9 \\
M062X/aug-cc-pVTZ & 1.400 & 1.360 & $105.7,108.3$ & \pm 90.8 \\
M062X/aug-cc-pVQZ & 1.399 & 1.357 & $105.7,108.5$ & \pm 91.0 \\
B3LYP/aug-cc-pVTZ & 1.440 & 1.377 & $106.6,109.3$ & \pm 93.6 \\
B3LYP/6-31g(d) & 1.440 & 1.386 & $105.8,108.7$ & \pm 90.5 \\
MP2(full)/6-31g(d) & 1.365 & 1.340 & $105.6,108.2$ & \pm 90.1 \\
Experiment & - & - & - & - \\
CCSD(T)/cc-pVTZ & 1.444 & 1.385 & $105.5,108.3$ & \pm 91.3 \\
\hline
\end{tabular}

${ }^{\mathrm{a}}$ Ref. [22]. ${ }^{\mathrm{b}}$ Ref. [17]. ${ }^{\mathrm{c}}$ Ref. [12]. ${ }^{\mathrm{d}}$ Ref. [31]. ${ }^{\mathrm{e}}$ CCSD(T)/TZ2P: Ref. [21]. ${ }^{\mathrm{f}}$ Ref. [11]. ${ }^{\mathrm{g}}$ CCSD/6311+G(d): Ref. [25]. ${ }^{\mathrm{h}}$ CCSD(T)/cc-pVTZ: Ref. [19]. 
Table 2. The expectation value of the total spin $\left\langle\mathrm{S}^{2}\right\rangle$.

\begin{tabular}{ccc}
\hline \multirow{2}{*}{ Molecule } & Method/Basis set & $\left\langle\mathbf{S}^{2}\right\rangle$ \\
\hline FOO & M06/aug-cc-pVDZ & 0.756 \\
& M06/aug-cc-pVTZ & 0.754 \\
& M06/aug-cc-pVQZ & 0.754 \\
& M062X/aug-cc-pVDZ & 0.782 \\
& M062X/aug-cc-pVTZ & 0.750 \\
& M062X/aug-cc-pVQZ & 0.750 \\
& B3LYP/aug-cc-pVTZ & 0.750 \\
& B3LYP/6-31g(d) & 0.7509 \\
& & \\
& M06/aug-cc-pVDZ & 0.892 \\
& M06/aug-cc-pVTZ & 0.782 \\
& M06/aug-cc-pVQZ & 0.782 \\
& M062X/aug-cc-pVDZ & 0.803 \\
& M062X/aug-cc-pVTZ & 0.780 \\
& M062X/aug-cc-pVQZ & 0.807 \\
& B3LYP/aug-cc-pVTZ & 0.790 \\
& B3LYP/6-31g(d) & 0.776 \\
\hline
\end{tabular}


Table 3. Enthalpies of formation for chlorine oxides and related hydrides.

\begin{tabular}{|c|c|c|c|c|c|c|}
\hline \multirow{2}{*}{ Compd. } & \multicolumn{6}{|c|}{$\Delta \mathbf{H}_{f, 298 \mathrm{~K}}^{\circ}\left(\mathrm{kcal} \mathrm{mol}^{-1}\right)$} \\
\hline & ccCA-S3 & $\mathrm{M}^{2} 6^{\mathrm{a}}$ & M06-2X & G3 & G3B3 & Expt. \\
\hline $\mathrm{ClO}$ & 25.3 & 23.1 & 23.5 & 25.9 & 26.7 & $24.29 \pm 0.03^{\mathrm{b}}$ \\
\hline $\mathrm{ClO}_{2}$ & 23.9 & 21.2 & 26.8 & 26.8 & 27.6 & $22.6 \pm 0.3^{\mathrm{b}, \mathrm{c}}$ \\
\hline $\mathrm{ClO}_{3}$ & 44.0 & 40.5 & 50.2 & 48.3 & 51.0 & $46 \pm 3^{\mathrm{d}}$ \\
\hline $\mathrm{ClO}_{4}$ & 57.7 & 52.6 & 65.4 & 66.0 & 65.5 & - \\
\hline HOCl & -19.5 & -18.0 & -19.3 & -17.4 & -16.9 & $-18.4 \pm 0.03^{\mathrm{e}}$ \\
\hline HOClO & 3.5 & 4.6 & 6.5 & 6.4 & 7.3 & - \\
\hline $\mathrm{HOClO}_{2}$ & -2.8 & -3.9 & 3.3 & 2.0 & 3.8 & - \\
\hline $\mathrm{HOClO}_{3}$ & -0.8 & -3.4 & 5.5 & 5.6 & 8.7 & - \\
\hline MAD & 1.1 & 2.1 & 2.5 & 2.3 & 3.5 & - \\
\hline
\end{tabular}

\footnotetext{
${ }^{\mathrm{a}} \mathrm{M} 06$ and M06-2X in conjunction with aug-cc-pV(Q+d)Z for chlorine and aug-cc-pVQZ for oxygen and hydrogen.

${ }^{\mathrm{b}}$ Ref. [76]. ${ }^{\mathrm{c}}$ Ref. [77]. ${ }^{\mathrm{d}}$ Ref. [70-72] ${ }^{\mathrm{e}}$ Ref. [78].
} 
Table 4. Enthalpies of formation for the oxygen fluoride species using M06 and M06-2X paired with the correlation consistent basis sets. $\Delta \mathrm{H}_{f, 298 \mathrm{~K}}^{\circ}\left(\mathrm{kcal} \mathrm{mol}^{-1}\right)$

\begin{tabular}{|c|c|c|c|c|c|c|c|}
\hline \multirow{2}{*}{ Compd. } & \multicolumn{3}{|l|}{ M06 } & \multicolumn{3}{|c|}{ M06-2X } & \multirow{2}{*}{$\begin{array}{c}\text { Reference } \\
\text { data }^{a}\end{array}$} \\
\hline & $\mathrm{aDZ}$ & aTZ & $\mathrm{aQZ}$ & $\mathrm{aDZ}$ & aTZ & $\mathrm{aQZ}$ & \\
\hline FO & 29.6 & 28.5 & 28.1 & 29.1 & 28.3 & 27.5 & $26.1 \pm 2.4$ \\
\hline FOH & -16.9 & -17.3 & -17.7 & -16.4 & -18.3 & -18.6 & $-23.16 \pm 1.2$ \\
\hline FOF & 12.9 & 9.7 & 9.6 & 11.5 & 9.6 & 8.7 & $5.9 \pm 0.5$ \\
\hline FOO & 10.6 & 9.5 & 9.0 & 18.3 & 16.0 & 14.5 & $6.1 \pm 0.5$ \\
\hline FOOH & -6.0 & -6.9 & -7.6 & -5.6 & -7.6 & -8.4 & $-10.4 \pm 1.0^{\mathrm{b}}$ \\
\hline FOOF & 14.1 & 11.3 & 11.2 & 18.6 & 16.9 & 15.5 & $4.6 \pm 0.5$ \\
\hline FOOO & 40.3 & 37.8 & 36.7 & 43.4 & 43.2 & 41.3 & - \\
\hline FOOOH & 4.9 & 3.5 & 2.6 & 6.2 & 4.1 & 2.9 & - \\
\hline FOOOF & 35.3 & 31.5 & 30.9 & 34.4 & 32.7 & 30.9 & $26.6^{\mathrm{c}}$ \\
\hline MAD & 6.3 & 4.4 & 4.0 & 7.7 & 6.0 & 5.2 & \\
\hline $\begin{array}{l}\text { MAD w/o } \\
\text { FOOF }\end{array}$ & 5.7 & 4.0 & 3.5 & 6.7 & 5.0 & 4.3 & \\
\hline
\end{tabular}

aDZ: aug-cc-pVDZ

aTZ: aug-cc-pVTZ

aQZ: aug-cc-pVQZ

${ }^{a}$ NIST-JANAF Tables: Ref. [36,37].

${ }^{\mathrm{b}} \mathrm{CCSD}(\mathrm{T}) / \mathrm{ANO} 4:$ Ref. [21].

${ }^{\mathrm{c}}$ Extrapolated CCSD(T)/aug-cc-pV(T,Q)Z: Ref. [19]. 
Table 5. Enthalpies of formation for the oxygen fluoride species using the four different variant of ccCA method.

\begin{tabular}{|c|c|c|c|c|c|}
\hline \multirow{2}{*}{ Compd. } & \multicolumn{5}{|c|}{$\Delta \mathbf{H}_{f, 298 \mathrm{~K}}^{\circ}\left(\mathrm{kcal} \mathrm{mol}^{-1}\right)$} \\
\hline & ccCA-P & ccCA-S3 & ccCA-PS3 & ccCA-S4 & Reference data $^{\mathrm{a}}$ \\
\hline FO & 27.3 & 27.0 & 27.2 & 27.3 & $26.1 \pm 2.4$ \\
\hline FOH & -21.1 & -21.6 & -21.4 & -21.1 & $-23.16 \pm 1.2$ \\
\hline FOF & 6.6 & 6.2 & 6.4 & 6.7 & $5.9 \pm 0.5$ \\
\hline FOO & 8.1 & 7.5 & 7.8 & 8.1 & $6.1 \pm 0.5$ \\
\hline FOOH & -11.0 & -11.7 & -11.3 & -10.9 & $-10.4 \pm 1.0^{\mathrm{b}}$ \\
\hline FOOF & 9.4 & 8.7 & 9.0 & 9.4 & $4.6 \pm 0.5$ \\
\hline FOOO & 31.8 & 31.0 & 31.4 & 31.8 & - \\
\hline FOOOH & -0.7 & -1.6 & -1.1 & -0.6 & - \\
\hline FOOOF & 27.8 & 26.8 & 27.3 & 27.8 & $26.6^{c}$ \\
\hline MAD & 1.8 & 1.4 & 1.6 & 1.8 & - \\
\hline MAD w/o FOOF & 1.3 & 0.9 & 1.1 & 1.3 & - \\
\hline
\end{tabular}

${ }^{a}$ NIST-JANAF Tables: Ref. [36,37].

${ }^{\mathrm{b}} \mathrm{CCSD}(\mathrm{T}) / \mathrm{ANO} 4:$ Ref. [21].

${ }^{\mathrm{c}}$ Extrapolated CCSD(T)/aug-cc-pV(T,Q)Z: Ref. [19]. 
Table 6. Calculated enthalpies of formation for the oxygen fluoride species using all methods and the MADs of these methods with respect to the reference data.

\begin{tabular}{|c|c|c|c|c|c|c|}
\hline \multirow{2}{*}{ Compd. } & \multicolumn{6}{|c|}{$\Delta \mathrm{H}_{f, 298 \mathrm{~K}}^{\circ}\left(\mathrm{kcal} \mathrm{mol}^{-1}\right)$} \\
\hline & ccCA-S3 & M06 $^{\mathrm{a}}$ & M06-2X & G3 & G3B3 & Reference data $^{\mathrm{b}}$ \\
\hline FO & 27.0 & 28.1 & 27.5 & 26.1 & 26.5 & $26.1 \pm 2.4$ \\
\hline FOH & -21.6 & -17.7 & -18.6 & -20.4 & -20.1 & $-23.16 \pm 1.2$ \\
\hline FOF & 6.2 & 9.6 & 8.7 & 6.5 & 6.8 & $5.9 \pm 0.5$ \\
\hline FOO & $7.5^{\mathrm{e}}$ & $9.0^{\mathrm{f}}$ & $14.5^{\mathrm{f}}$ & $7.1^{\mathrm{g}}$ & 7.0 & $6.1 \pm 0.5$ \\
\hline FOOH & -11.7 & -7.6 & -8.4 & -10.3 & -10.2 & $-10.4 \pm 1.0^{\mathrm{c}}$ \\
\hline FOOF & 8.7 & 11.2 & 15.5 & 9.3 & 8.9 & $4.6 \pm 0.5$ \\
\hline FOOO & $31.0^{\mathrm{e}}$ & $36.7^{\mathrm{f}}$ & $41.3^{\mathrm{f}}$ & $30.1^{\mathrm{g}}$ & $30.1^{\mathrm{g}}$ & - \\
\hline FOOOH & -1.6 & 2.6 & 2.9 & 0.2 & -0.3 & - \\
\hline FOOOF & 26.8 & 30.9 & 30.9 & 27.8 & 27.3 & $26.6^{\mathrm{d}}$ \\
\hline MAD & 1.4 & 4.0 & 5.2 & 1.5 & 1.5 & - \\
\hline MAD w/o FOOF & 0.9 & 3.5 & 4.3 & 0.9 & 0.9 & - \\
\hline
\end{tabular}

${ }^{a}$ M06 and M06-2X in conjunction with aug-cc-pVQZ.

${ }^{\mathrm{b}}$ NIST-JANAF Tables: Ref. [36,37].

${ }^{\mathrm{c}} \mathrm{CCSD}(\mathrm{T}) / \mathrm{ANO} 4:$ Ref. [21].

${ }^{\mathrm{d}}$ Extrapolated CCSD(T)/aug-cc-pV(T,Q)Z: Ref. [19].

${ }^{\mathrm{e}}$ Using RO-ccCA.

${ }^{\mathrm{f}}$ Using ROM06 and ROM06-2X.

${ }^{\mathrm{g}}$ Using G3-RAD. 
Table 7. Calculated enthalpies of formation for the oxygen fluoride species using M06 and M06$2 \mathrm{X}$ methods based on B3LYP/aug-cc-pVTZ geometries.

\begin{tabular}{|c|c|c|c|}
\hline \multirow{2}{*}{ Compd. } & \multicolumn{3}{|c|}{$\Delta \mathbf{H}_{f, 298 \mathrm{~K}}^{\circ}\left(\mathrm{kcal} \mathrm{mol}^{-1}\right)$} \\
\hline & B3LYP $^{a} / / M_{06}^{b}$ & B3LYP $^{\mathrm{a}} / / \mathbf{M 0 6}^{-2 X^{b}}$ & Reference data $^{c}$ \\
\hline FO & 28.4 & 27.7 & $26.1 \pm 2.4$ \\
\hline FOH & -17.5 & -18.5 & $-23.16 \pm 1.2$ \\
\hline FOF & 10.2 & 9.3 & $5.9 \pm 0.5$ \\
\hline FOO & 9.3 & 15.0 & $6.1 \pm 0.5$ \\
\hline FOOH & -6.9 & -7.7 & $-10.4 \pm 1.0^{\mathrm{d}}$ \\
\hline FOOF & 11.8 & 19.9 & $4.6 \pm 0.5$ \\
\hline FOOO & 34.7 & 47.5 & - \\
\hline FOOOH & 4.9 & 4.5 & - \\
\hline FOOOF & 31.8 & 32.1 & $26.6^{\mathrm{e}}$ \\
\hline MAD & 4.5 & 6.0 & - \\
\hline MAD w/o FOOF & 4.0 & 4.4 & - \\
\hline
\end{tabular}

${ }^{\text {a } B 3 L Y P / a u g-c c-p V T Z . ~}$

${ }^{\mathrm{b}}$ M06/aug-cc-pVQZ and M06-2X/aug-cc-pVQZ

${ }^{\mathrm{c}}$ NIST-JANAF Tables: Ref. [36,37].

${ }^{\mathrm{d}} \mathrm{CCSD}(\mathrm{T}) / \mathrm{ANO} 4:$ Ref. [21].

${ }^{\mathrm{e}}$ Extrapolated CCSD(T)/aug-cc-pV(T,Q)Z: Ref. [19]. 
Table 8. Calculated Enthalpies of formation for the oxygen fluoride species using all methods and the MADs of these methods with respect to the ATcT values.

\begin{tabular}{ccccccc}
\hline \multirow{2}{*}{ Compd. } & \multicolumn{5}{c}{$\Delta \mathbf{H}_{f, \mathbf{2 9 8} \mathbf{~ K}}\left(\mathbf{k c a l ~ m o l}^{-\mathbf{1}}\right)$} \\
\cline { 2 - 6 } & $\mathbf{c c C A - S 3}$ & $\mathbf{M 0 6}^{\mathbf{a}}$ & $\mathbf{M 0 6 - 2 \mathbf { X } ^ { \mathbf { a } }}$ & $\mathbf{G 3}$ & $\mathbf{G 3 B 3}$ & $\mathbf{A T c T}^{\mathbf{b}}$ \\
\hline FO & 27.0 & 28.1 & 27.5 & 26.1 & 26.5 & $26.51 \pm 0.04$ \\
FOH & -21.6 & -17.7 & -18.6 & -20.4 & -20.1 & $-20.85 \pm 0.05$ \\
FOF & 6.2 & 9.6 & 8.7 & 6.5 & 6.8 & $5.91 \pm 0.06$ \\
FOOH & $7.5^{\mathrm{e}}$ & $9.0^{\mathrm{f}}$ & $14.5^{\mathrm{f}}$ & $7.1^{\mathrm{g}}$ & 7.0 & $5.99 \pm 0.06$ \\
FOOF & -11.7 & -7.6 & -8.4 & -10.3 & -10.2 & - \\
FOOO & 8.7 & 11.2 & 15.5 & 9.3 & 8.9 & $8.04 \pm 0.09$ \\
FOOOH & -1.6 & 2.6 & 2.9 & 0.2 & -0.3 & - \\
FOOOF & 26.8 & 30.9 & 30.9 & 27.8 & 27.3 & $26.63 \pm 1.86$ \\
\hline MAD & 0.6 & 3.1 & 4.7 & 0.8 & 0.7 & \\
\hline
\end{tabular}

${ }^{\mathrm{a}} \mathrm{M} 06$ and M06-2X in conjunction with aug-cc-pVQZ.

${ }^{\mathrm{b}} \mathrm{ATcT}$ : Ref. [74,75].

${ }^{\mathrm{c}}$ Using RO-ccCA.

${ }^{\mathrm{d}}$ Using ROM06 and ROM06-2X.

${ }^{\mathrm{e}}$ Using G3-RAD. 


\section{Graphical abstract}

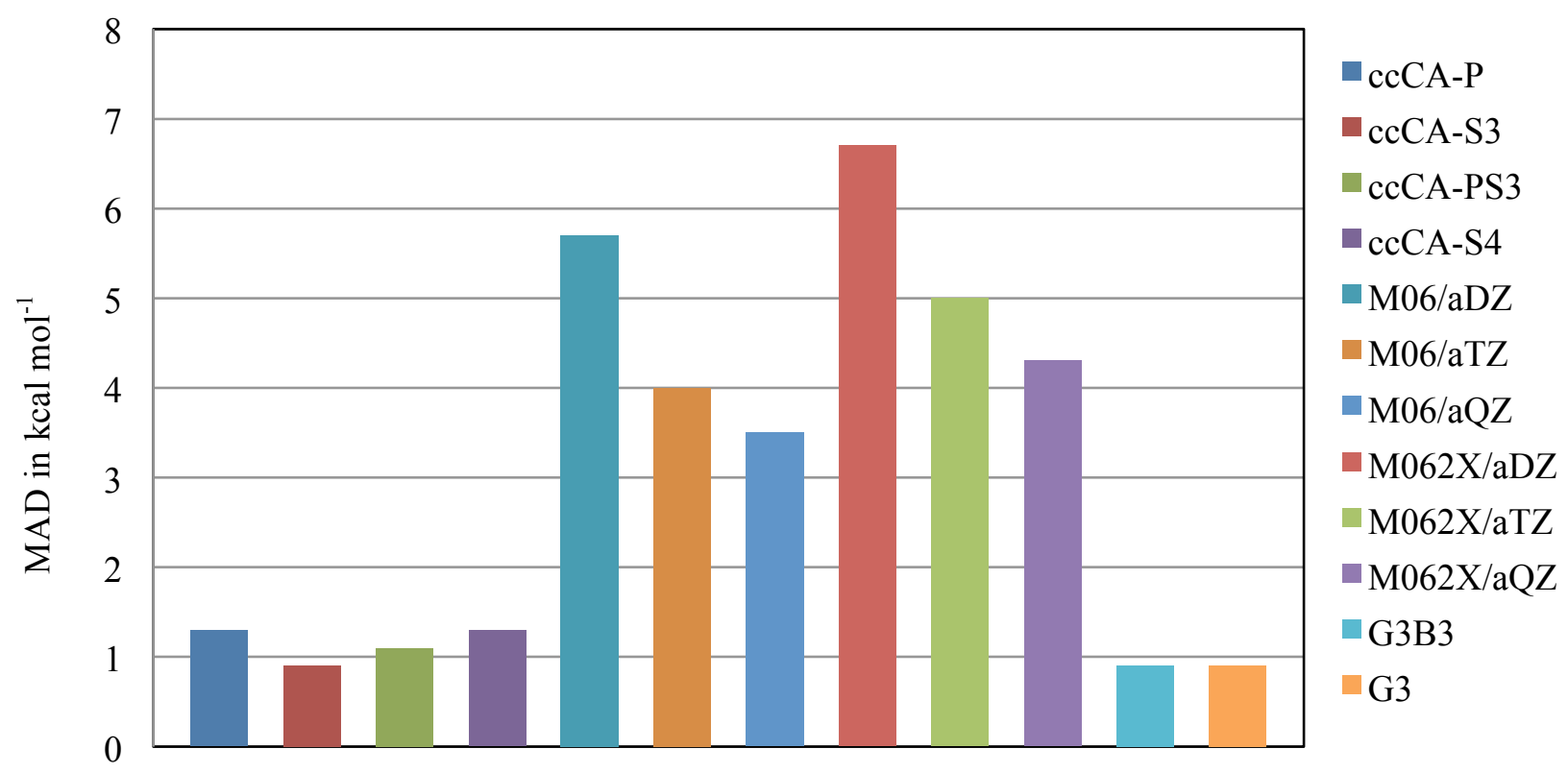

MADs of the enthalpies of formation of oxygen fluoride species (excluding FOOF). 